NBER WORKING PAPER SERIES

\title{
STATE HEALTH INSURANCE MANDATES AND LABOR MARKET OUTCOMES: NEW EVIDENCE ON OLD QUESTIONS
}

\author{
Yaa Akosa Antwi \\ Johanna Catherine Maclean \\ Working Paper 23203 \\ http://www.nber.org/papers/w23203 \\ NATIONAL BUREAU OF ECONOMIC RESEARCH \\ 1050 Massachusetts Avenue \\ Cambridge, MA 02138 \\ February 2017, Revised February 2018
}

This research was conducted with restricted access to Bureau of Labor Statistics (BLS) data. The views expressed here do not necessarily reflect the views of the BLS, nor those of of the National Bureau of Economic Research. We thank James Bailey, John Bowlis, Marcus Dillender, Sarah Hammersma, Andrew Sfekas, Douglas Webber, and seminar participants at the 2016 American Society of Health Economists Conference and the 2016 Association for Public Policy and Management Fall Research Conference for helpful comments. All errors are our own.

NBER working papers are circulated for discussion and comment purposes. They have not been peer-reviewed or been subject to the review by the NBER Board of Directors that accompanies official NBER publications.

(C) 2017 by Yaa Akosa Antwi and Johanna Catherine Maclean. All rights reserved. Short sections of text, not to exceed two paragraphs, may be quoted without explicit permission provided that full credit, including $\odot$ notice, is given to the source. 
State Health Insurance Mandates and Labor Market Outcomes: New Evidence on Old Questions Yaa Akosa Antwi and Johanna Catherine Maclean

NBER Working Paper No. 23203

February 2017, Revised February 2018

JEL No. H2,I13,J3

\begin{abstract}
In this study we re-visit the relationship between private health insurance mandates, access to employer-sponsored health insurance, and labor market outcomes. Specifically, we model employer-sponsored health insurance access and labor market outcomes across the lifecycle as a function of the number of high cost mandates in place at labor market entrance. Our analysis draws on a long panel of workers from the National Longitudinal Survey of Youth 1979 and exploits variation in five high cost state mandates between 1972 and 1989. Four principal findings emerge from our analysis. First, we find no strong evidence that high cost state health insurance mandates discourage employers from offering insurance to employees. Second, employers adjust both wages and labor demand to offset mandate costs, suggesting that employees place some value on the mandated benefits. Third, the effects are persistent, but not permanent. Fourth, the effects are heterogeneous across worker types. These findings have implications for thinking through the full labor market effects of health insurance expansions.
\end{abstract}

\author{
Yaa Akosa Antwi \\ Johns Hopkins University \\ Carey Business School \\ 100 International Drive \\ Baltimore, MD 21202 \\ y.akosa.antwi@jhu.edu \\ Johanna Catherine Maclean \\ Department of Economics \\ Temple University \\ Ritter Annex 869 \\ Philadelphia, PA 19122 \\ and NBER \\ catherine.maclean@temple.edu
}




\section{Introduction}

Private health insurance historically has been regulated at the state level in the United States (Morrisey 2014). In particular, states have regulated the generosity and scope of private health insurance coverage through the implementation of legislation commonly referred to as "mandates" since the 1940s. Mandates typically stipulate coverage for specific treatments (e.g., mental health), providers (e.g., optometrists), and population categories (e.g., dependents) within the private market (Morrisey 2014). Pennsylvania passed the first mandate in 1949: requiring coverage for healthcare services provided by osteopaths and dentists (Laugesen et al. 2006). The number of mandates has increased substantially over time, from roughly 1,000 mandates in 1991 (Gruber 1994b) to 2,156 mandates in 2010 (Bunce and Wieske 2010).

The key economic argument for mandates is resolution of the adverse selection problem (Lahey 2012): only those individuals who expect to utilize a particular healthcare service are willing to pay for insurance that covers this service, which leads to a cycle of increasing premiums and a smaller, less healthy pool of beneficiaries. ${ }^{1}$ Positive externalities from healthcare interventions (e.g., vaccines) also motivate the use of mandates. Advocates contend that mandates are welfare enhancing as they compel private insurers to provide an equitable and appropriate level of coverage (Gruber 1994b). Mandate critics argue that these regulations unduly increase labor costs, contribute to the overall rise in healthcare costs, and, consequently, the decline of employer-sponsored health insurance (ESI) within the U.S. (Litow 2002).

The contentious policy debate on the merits and demerits of mandates is not close to resolution. The inability to reach a consensus about the value of mandated benefits is, in part, due to the conflicting research findings on mandate effects. For example, a series of studies documents that mandates increase access to valuable healthcare services (Dave and Mukerjee 2011, Maclean, Popovici, and Stern 2017, Akosa Antwi, Moriya, and Simon 2015) and improve health (Courtemanche and Zapata 2014, Popovici, Maclean, and French 2017) without substantially distorting the labor market (Kaestner and Simon 2002). A different set of studies suggests mandated health insurance benefits in private markets may have negative consequences, such as terminated health insurance coverage (Gabel and Jensen 1992), increased insurance costs (Bailey and Blascak 2016, Depew and Bailey 2015), distortions in the labor market (Bailey and Webber 2016), and moral hazard (Klick and Stratmann 2006) with limited

\footnotetext{
${ }^{1}$ In the extreme, the market will enter a "death spiral" in which the premiums become so high that no individuals are willing to purchase insurance leading to a collapse of the market.
} 
impact on access to healthcare services (Pacula and Sturm 2000, Sturm 2000).

In this study we explore the persistent effect of mandated benefits in private insurance markets on access to ESI and labor market outcomes among new labor market entrants. As such we add new information to the large economic literature on the effect of mandated benefits on U.S. labor markets. While our study cannot reconcile the controversy within the mandated benefits literature, we attempt to shed light on a question that, to the best of our knowledge, has not yet been studied. Specifically, we ask, Are there persistent effects of high cost mandates on access to ESI and labor market outcomes for new labor market entrants? In other words, (i) do high cost mandates affect access to ESI and labor market outcomes among new labor market entrants; and (ii) will there be persistent differences over the lifecycle of two workers, one who enters a labor market characterized by highly regulated private insurance contracts and the other who enters a labor market with limited regulation of private insurance contracts? Economic theories that allow for labor market frictions suggest that shocks to labor demand, such as mandates, at initial labor market entrance can lead to persistent effects. Broadly, these theories suggest that a worker's initial compensation package can persistently effect his compensation and labor supply profiles. Thus, shocks to labor demand can have long-lasting implications for new labor market entrants.

We consider the following outcomes: whether an employee has an offer of ESI, hourly wages, and labor supply (weeks worked per year and the probability of full-time employment). Our contributions to the literature are twofold. First, by using private health insurance mandates data spanning 1973 to 1990 , we leverage variation in the number and scope of several costly mandated benefits that were implemented prior to widespread self-insurance on the part of employers. Second, we explore dynamics of mandate effects across the lifecycle.

To answer this question, we draw a long panel of workers from the National Longitudinal Survey of Youth 1979 (NLSY79). The NLSY79 tracks workers from initial labor market entrance through mid-career when workers are in their mid-50s. The mandated benefits we study are: alcohol abuse treatment, illicit drug abuse treatment, mental health treatment, chiropractors, and continuing coverage for terminated employees and their dependents. During our study period, health insurance mandates accounted for over $30 \%$ of employers' health insurance costs, with these specific mandates generating over $50 \%$ of these costs (Gruber 1994b). Moreover, self-insurance by employers - which is common in the current labor market and may allow firms to circumvent state insurance regulations - was relatively rare, with 
roughly $8 \%$ of firms self-insuring during our study period (McDonnell et al. 1986). Thus, the costly mandates we study may have had a greater "bite" during the period we study compared to recent periods. We estimate differences-in-differences models that control for time-invariant and time-varying state-level factors that may be correlated with both the passage of high cost mandates, ESI offers, and labor market outcomes. Over our study period, numerous states implemented at least one or more of the mandates we study, offering us substantial variation for identification.

We find no evidence that the state health insurance mandates we study discourage employers from offering ESI, but employers reduce wages and labor demand (measured by weeks and hours worked) to offset the cost of mandates. Collectively, these findings suggest that employees value the mandated benefits, but not fully. The effects we estimate are persistent but not permanent: they dissipate with time spent in the labor market. However, our findings suggest a high degree of persistence as we observe that effects can endure for 12 years or more, depending on the outcome, after labor market entrance. Lastly, the adverse effects appear to be concentrated among workers who began their careers with small employers and non-unionized employers, and lesser skill workers (workers with no college education). We confirm these findings in the Current Population Survey (CPS), a large-scale state-representative dataset that is commonly utilized in the health insurance mandates literature. While our CPS results are in line with our NLSY79 findings for wages and labor supply, we find evidence in the CPS that high cost mandates at labor market entrance persistently, but not permanently, reduce the probability that an individual is covered by ESI. We hypothesize that an explanation for our ESI coverage finding could be post mandate, employers may increase employee cost-sharing (e.g., premiums, deductibles, and copays) which may lead to lower take up among employees.

The remainder of this paper is organized as follows. Section 2 reviews the economics of mandated benefits and related literature. Section 3 outlines our conceptual framework and hypotheses. Our data, variables, and methods are described in Section 4. Section 5 reports our main results, while extensions to the main analysis and robustness checking are reported in Section 6. Finally, Section 7 concludes.

\section{Empirical evidence on health insurance mandates}

A comprehensive review of the vast literature on ESI and labor market effects of health insurance mandates is beyond the scope of our study. Thus, for brevity, we focus our attention on studies that are closely related to our research question: those that examine the concurrent 
effect of mandates and rising health insurance cost on ESI, wages, and labor supply. ${ }^{2}$ We refer readers to reviews by Jensen and Morrisey (1999), Monheit et al. (2007), Lahey (2012), and Morrisey (2014) for more details.

\subsection{Employer sponsored health insurance}

Gabel and Jensen (1992) examine the effect of state insurance regulation on small $(<100$ workers) employers' decisions to offer health insurance coverage. Using data on 1,320 small employers, the authors find mixed evidence on mandate effects. Continuation-of-coverage mandates decrease the likelihood that a small employer offers ESI whereas drug abuse treatment mandates increase this probability. Overall, implementation of the two mandates reduces the likelihood that a small employer offers ESI. Gruber (1994b) uses data from the CPS and five high cost mandates to investigate the mandate-ESI relationship. ${ }^{3}$ The author finds no evidence that mandates effect employers' propensity to offer ESI. Subsequent studies support Gruber's null finding (Cseh 2008, Kaestner and Simon 2002, Bao and Sturm 2004, Sturm 2000).

\subsection{Wages and labor supply}

In a seminal study, Gruber (1994a) evaluates the labor market response to state and federal mandates for comprehensive coverage for childbirth among married women of childbearing age (i.e., the target population of this mandate). Using CPS data, Gruber tests the effect of the mandates on wages, hours worked, and employment of married women of childbearing age. He finds evidence that employers shift the cost of mandated maternity benefits to married women of childbearing age, but no evidence that mandates affect such women's hours worked or employment propensity. The decrease in wages combined with no change in hours or employment suggests that these women value the mandated benefit.

Kaestner and Simon (2002), using CPS data, find that the number of state-mandated insurance benefits have no effect on wages and weeks of work. However, the authors show that the number of mandates increases weekly work hours.

Cseh (2008) studies the effect of state mental health mandates on labor market outcomes and finds that these mandates reduce wages, suggesting that employees value the mandated benefit, but no evidence that measures of labor supply are affected by passage of this mandate. Andersen (2015) builds on Cseh's work to study heterogeneity in the effect of mental health

\footnotetext{
2 To the best of our knowledge, at the time of writing, no studies have examined persistent effects of mandated benefits as we do here.

${ }^{3}$ The five high cost mandates are: mandated minimum benefits for alcohol abuse treatment, drug abuse treatment, and mental illness; mandated coverage for chiropractic services; and mandated continuation of health insurance benefits for terminated employees and their dependents. We examine the same high cost mandates in our study.
} 
mandates on labor market outcomes. Specifically, Anderson shows that among employees with poor mental health, mandates increase wages and working hours. ${ }^{4}$ Relatedly, Lahey (2012) finds that wages are unaffected by infertility mandates, though labor supply decreases by 1.07 weeks per year among women of childbearing age.

Overall, the literature on the effects of mandates on health insurance and labor market outcomes is somewhat mixed. ${ }^{5}$ However, while mixed, the literature does suggest some scope for mandates to effect the labor market outcomes examined in this study.

\subsection{Rising health insurance cost and labor market outcomes}

A related series of studies relevant to our work has investigated how rising healthcare costs generally affect labor market outcomes. Cutler and Madrian (1998) document that increases in health insurance costs lead to increases in average hours worked in the CPS and Survey of Income Program Participation. The authors interpret their findings to imply that, due to the increased cost per employee, employers opt to extract more work time from incumbent employees rather than hiring new employees. Baicker and Chandra (2006) assess the effect of rising health insurance premiums on wages, employment, and the distribution of full-time and part-time workers. Using malpractice cost as an instrument for estimated health insurance premiums, the authors find that workers bear some of the cost of rising health insurance premiums in the form of lower wages. Institutional constraints, however, prevent employers from passing on all costs to workers. In addition, as costs rise, employers and workers have an incentive to move from full-time employment with benefits to part-time employment without.

Research on the public sector (school districts), which has a sizable union presence and is less affected by market forces than the private sector, finds that health insurance cost increases are partially offset by increases in premiums (Lubotsky and Olson 2015), with no measurable change in wages or salaries (Lubotsky and Olson 2015, Clemens and Cutler 2014), employment, or quality of employed workers (Lubotsky and Olson 2015).

As in the mandate literature, findings from studies that focus on the labor market effects of rising healthcare costs suggest that employers pass some healthcare costs on to employees.

\section{Conceptual framework}

We next review several strands of economic theory that point toward (i)

\footnotetext{
${ }^{4}$ Additionally, Andersen (2015) finds that mandates increase the probability of an ESI offer and ESI coverage among those with poor mental health.

${ }^{5}$ Lahey (2012) argues that the lack of consensus in the literature is not surprising. Because mandates vary in terms of scope, costs to employers, affected population, and characteristics, economic theory necessarily predicts the mixed results observed within the literature.
} 
contemporaneous effects of mandates on access to ESI and labor market outcomes, and (ii) persistent effects of mandates on these outcomes.

\subsection{A brief review of the economics of health insurance mandates}

Summers (1989) provides one of the early economic analyses of health insurance mandates on labor market outcomes. Prior to implementation of a mandate, the labor market is in equilibrium at the intersection $D_{1}$ and $S_{1}$, with employment level $E_{1}$ and wages of $W_{1}$ as depicted in Figure 1. Summers, assuming that the cost of the mandate is a per hour rate, argues that health insurance mandates increase labor costs and should, all else equal, lead to a decrease in demand for labor among employers by the cost of the mandate, from $D_{1}$ to $D_{2}$. Thus, the mandate should lead to a lower level of employment and wages $\left(E_{2}^{\prime}, W_{2}^{\prime}\right)$. However, if employees value the mandate, then this valuation will lead to an increase in labor supply (from $S_{1}$ to $S_{2}$ ). The labor supply increase will have two effects: it will attenuate the employment decline and increase the wage decline. At the new equilibrium, wages and employment will fall $\left(E_{2}, W_{2}\right)$. The extent to which the mandate affects wages and employment levels is determined by employees' valuation of the benefit.

If employees fully value the benefit, the incidence of the mandate will be entirely passed on to the employees in terms of lower wages, and there will be no effect on employment levels. Alternatively, if employees do not value the mandated benefit, costs will borne by employers, wages will be unchanged, and overall employment will decline to offset mandate costs.

Intermediate valuations of the mandated benefit by employees will lead to both lower wages and employment levels, with the relative magnitudes of these effects determined by employee preferences and the elasticities of labor supply and demand. Summers (1989) notes that features of the U.S. labor market, such as minimum wages and anti-discrimination laws, limit employers' ability to reduce wages to offset costs.

Subsequent economic research offers a number of potential extensions to the Summers framework. Sloan and Conover (1998) highlight the possibility that, if mandates become too costly, employers may elect to self-insure. Self-insured firms are exempt from state regulations of the healthcare market under Employee Retirement Income Security Act of 1974 (ERISA). Gabel and Jensen (1992) note that employers, when faced with higher mandate costs, could choose to eliminate ESI altogether. Such actions would reduce the probability of access to ESI, but would mute wage and employment effects. ${ }^{6}$ Cutler and Madrian (1998) develop a model in

\footnotetext{
${ }^{6}$ Indeed, if employers drop ESI and wish to maintain the same level of compensation for employees, we might
} 
which employers may increase the labor supply of current employees rather than hire additional employees. ${ }^{7}$ Moreover, employers may opt to rely on part-time or temporary workers who are generally not eligible for employer-sponsored benefits such as health insurance. ${ }^{8}$

In summary, worker valuation of mandated benefit, institutional constraints on wages (e.g., minimum wage) and benefits (e.g., anti-discrimination laws), and the elasticities of labor supply and demand will determine the magnitude of the effect of mandates on ESI, wages, and labor supply. The ambiguity of theory offers premise for empirical study.

\subsection{Persistence}

A unique contribution of our study is that we explore the persistent effects of mandates for new labor entrants. While firms may absorb increased labor cost by increasing premiums for workers, they could also offset the cost through adjustment in wages. For instance, forwardlooking employers could offer less comprehensive compensation packages to new workers to account for higher non-wage compensation in the future and/or stifle wage growth of incumbent workers. We focus on new job market entrants since employers may find it more feasible to offer lower wage contracts to new hires than to reduce wages of existing employees when faced with increases in mandated benefits. ${ }^{9}$

To the best of our knowledge, there is no specific economic theory that considers the persistence of mandates on ESI or labor market outcomes. Thus, we draw on existing theories of career development to establish the possibility of a relationship between high cost mandates at labor market entry and employment outcomes across the life course.

Under the assumptions of perfect competition, the labor market operates as a spot market. In such a market, we would not expect initial conditions, including insurance regulations, to have a persistent effect as only current conditions are important for labor market outcomes. There are numerous reasons, however, to suspect that the U.S. labor market departs

\footnotetext{
expect wages (or other forms of compensation) to rise.

${ }^{7}$ Cutler and Madrian (1998) note that, in U.S. labor markets, ESI is generally not paid on a per hour rate (an assumption made by Summers [1989]) and instead is a fixed cost per employee.

${ }^{8}$ It is worth noting that if employers are able to pass some, or all, of the mandate costs to employees in the form of health insurance premium increases and/or additional cost sharing (e.g., copayments, deductibles) then the labor market implications of mandates would be muted (Bailey and Blascak 2016, Bailey 2014). We are unable to study this mechanism with our data.

${ }^{9}$ In particular, due to employment laws and concerns regarding employee morale and other factors, we hypothesize that employers may be more likely to offer lower wages to new hires, including new labor market entrants who have no previous reference point for their wages, than incumbent employees. We note that employer concerns regarding equity between different workers (i.e., new hires and incumbents) and the potential implications for reduced employee morale/productivity will likely prevent outrageously large declines in wage offers to new hires (Bewley 1998).
} 
from the perfectly competitive ideal (Webber 2015). More specifically, frictions in the labor market suggest persistent effects stemming from adverse career experiences.

A key source of frictions is the cost of switching from one job to another. Job switching involves search, training, time, financial, reputation, and psychic costs. Incomplete information about job opportunities and finite job offer arrival rates also lead to frictions. Broadly, frictions limit the ability of workers to switch from one job to another and therefore may force workers to remain stuck in poor job matches (Kondo 2015). While frictions effect all workers, they may be particularly salient for new labor market entrants as early career is a critical period of wage growth and skill accumulation (Neumark 2002, Topel and Ward 1992).

If mandates induce employers to cut labor costs by extracting additional hours from current workers rather than hiring new workers (Cutler and Madrian 1998), the quantity of job opportunities for new labor market entrants could be restricted. A job matching model predicts that individuals who leave school in such a market will experience a longer initial job search spell as there are fewer open jobs (Jovanovic 1979). Relatedly, if mandates affect the distribution of firms in the labor market (Bailey and Webber 2016), the types of firms that offer jobs may also be altered. Finally, lower wages attributable to mandates may lead employees who do not value the mandate to spend more time searching for a job that offers a wage at or above their reservation wage. Such a demand shock at labor market entrance could lead to new entrants accepting poor job matches, lower earnings, and temporary jobs with fewer hours.

If workers are initially mismatched to their jobs they may acquire the "wrong" human capital. Such accumulation may be particularly harmful for workers' wage profiles if a job requires firm- or task-specific, rather than general, human capital. If workers are unemployed at labor market entrance, or unemployed for longer spells as they search for a job, they may fail to accumulate human capital and/or experience depreciation in their human capital stock, causing these workers to fall behind in terms of their skills. Such limited human capital accumulation opportunities can lead to a persistently flatter wage profile (Genda, Kondo, and Ohta 2010).

In addition, the labor market may incorrectly interpret the first job placement as a measure of ability rather than luck (Oyer 2006). In such a model, a worker who enters the labor market during a negative shock to labor demand may carry the incorrect (negative) first placement signal throughout his career. Moreover, it is possible that worker preferences for job attributes (wage compensation vis-á-vis non-wage compensation, work hours, etc.) may be shaped by the initial job match (Oyer 2006). 
Supporting these hypotheses, there is ample evidence that adverse labor market conditions, often proxied with the unemployment rate, at labor market entrance have long-run effects on the earnings, access to ESI, job prestige, and labor supply of workers (Ellwood 1982, Kahn 2010, Oreopoulos, von Wachter, and Heisz 2012, Maclean 2014, Altonji, Kahn, and Speer 2016, Genda, Kondo, and Ohta 2010). ${ }^{10}$ For instance, using longitudinal Canadian data, Oreopoulos, von Wachter, and Heisz (2012) find that male college graduates who enter the labor market during a recession experience an initial earnings loss of $9 \%$ that persists for 10 years. Moreover, Genda, Kondo, and Ohta (2010) show that workers who leave school during periods of weak labor demand are persistently more likely to be unemployed. Maclean (2014) demonstrates that workers who enter the labor market during a recession are persistently less likely to have access to ESI and other forms of non-wage compensation. Although these studies explore the implications of a different type of labor demand shock (i.e., a decline in aggregate demand vs. an increase in price), they do open the door to the possibility that in general shocks experienced at labor market entrance may have long-lasting effects for workers.

\section{Data, variables, and methods}

\subsection{Data}

We draw data on a long panel of workers from the NLSY79. We use the geocoded data, which allows us to access information on state of residence. The original NLSY79 sample consists of 12,686 youth ages 14 to 22 in 1979 . The survey was administered annually by the Bureau of Labor Statistics between 1979 and 1993, and bi-annually from 1994 onward. These data are particularly well suited to our research question as the NLSY79 was specifically designed to track a cohort of workers as they transition into the labor market and throughout their career. We have information on ESI offers, wages, and labor supply. We are able to follow workers from labor market entrance, which we define as the first job held after leaving school, through mid-career. Specifically, in 2012 workers are in their early to mid-50s.

We focus on a sample of workers ages 18 to 54 (Gruber 1994b, Kaestner and Simon 2002). These exclusions, and others necessary to construct our analysis sample that are detailed later in the paper, leave us with a sample of 11,013 unique workers and 168,527 worker/year pairs (as discussed later, sample sizes differ across outcomes).

\footnotetext{
${ }^{10}$ We note that these studies explore the persistent effects of reduced aggregate labor demand while we examine an increase in the price of labor which should affect the quantity of labor demanded. We expect that, at the market level, both types of labor demand shocks can lead to changes in wage and non-wage compensation, and labor supply for workers.
} 


\subsection{ESI and labor market outcomes}

We focus on four outcomes using the ESI and labor market data available across years. NLSY79 respondents can list information, including the ESI offers and wage variables we study here, on multiple jobs. The number of jobs varies across survey years. For comparability across survey years we assume the first job reported by the respondent is the dominant job (Maclean 2014). The labor supply measures we examine are cumulative across all jobs.

First, we construct a binary indicator for whether or not a worker has access to ESI. The specific question wording in 1979 was, "Does your employer make health insurance available to you? Medical, surgical, or hospital insurance that covers injuries or major illnesses off the job?" 11 We code respondents as one if they report this offer, and zero otherwise. ${ }^{12}$

Next, we construct three labor market outcomes. First, we consider the hourly wage; we inflate nominal wages to 2012 dollars using the Consumer Price Index-Urban Consumers. We exclude workers with wages less than $\$ 1$ per hour and those with wages greater than $\$ 1,000$ per hour (Kahn 2010). Second, we construct two measures of the past year's labor supply: weeks worked (this variable is generated by NLSY79 administrators and reflects the sum of weeks worked across all jobs) and full-time work (an indicator variable coded 1 if the respondent usually works 35 or more hours per week, 0 otherwise). ${ }^{13}$ We take the logarithm of wages and weeks worked. ${ }^{14}$ Regression coefficient estimates have the interpretation of an approximation to the percent change. ${ }^{15}$ Due to differences in survey universe and item non-response, our sample sizes vary to some extent across outcomes. To preserve sample size, we rely on the unbalanced panel of workers. Results based on a sample with complete information on all four outcome variables are comparable. ${ }^{16}$

\footnotetext{
${ }^{11}$ The specific question wording has changed across survey years to some extent. Moreover, the ESI question was not asked in the 1981 round of the NSLY79, thus we do not have a value for this outcome in 1981. Interested readers can consult the NLSY79 codebook: http://www.bls.gov/nls/nlsy79.htm (accessed February 20th, 2018). ${ }^{12}$ Unlike previous studies that use the CPS to examine the impacts of state health insurance mandates on the provision of ESI (Kaestner and Simon 2002), we are able to isolate offers from take-up of ESI. Thus, we are able to avoid confounding offers with endogenous take-up decisions by employees. Although we argue that our ESI offer variable is advantageous, this variable has at least three important caveats. First, this variable captures whether an employee is aware of an offer of ESI. Respondents may decide not to take up this offer for myriad reasons. We are unable to capture such reasons here. Second, this variable does not measure the generosity of any offered ESI, thus we cannot assess whether the respondent's ESI offer covers the mandated benefits. Third, the ESI question described here is only asked to workers, and thus our findings may be vulnerable to sample-selection bias.

${ }^{13}$ We have estimated regression models in which the outcome variable is the logarithm of hours worked. Results are comparable and are reported in Supplementary Appendix Table 1.

${ }^{14} \mathrm{We}$ focus only on those individuals with positive values of these outcomes.

${ }^{15}$ Results using unlogged values of hourly wage and weeks worked are not appreciably different from those reported here. See Supplementary Appendix Table 1.

${ }^{16}$ Results are reported in Supplementary Appendix Table 2.
} 


\subsection{High cost health insurance mandates at school-leaving}

To measure the number of high cost mandates in place at labor market entrance, we use data on five high cost mandates for services, providers, and covered beneficiaries studied by Gruber (1994b). The mandates are: alcohol abuse treatment, illicit drug treatment, mental health treatment, coverage of chiropractic services, and continuing coverage.

To investigate the effect of high cost mandates at the time of labor market entrance, we must locate the state and year in which each individual left school, the location and period in which most students enter the labor market. A limitation of the NLSY79 data is that we only have state of residence beginning in 1979 (the first year of the survey), but many individuals in our sample entered the labor market before this year (respondents are ages 14 to 22 in 1979). We use state of birth as a proxy for the labor market entrance state for all workers. We exclude respondents with a missing birth state or who were born outside the U.S. Use of the birth state leads to measurement error for those individuals who crossed state lines between birth and labor market entrance. However, for the study period where we observe most respondents enter the labor market, less than $3 \%$ of the U.S. population moved across state lines annually (Bureau of Labor Statistics, 1976). Thus, we suspect that measurement error is not substantial. Moreover, as a sensitivity check, we have re-estimated our models using the state of residence at age 14, state of residence in 1979 for those who left school in 1979 or earlier, and interview state for those who left school after 1979 to proxy the labor market entrance state. Results are not appreciably different from those reported here. ${ }^{17}$ We refer to birth states as "labor market entrance" states henceforth in the paper.

We locate the year of labor market entrance using retrospective information on schoolleaving collected between 1979 and 1998. Non-enrolled NLSY79 respondents are asked to report the year in which they left school. If a respondent indicated that they completed no formal education, we exclude them from the analysis sample as we cannot locate a labor market entrance year. We focus on the sample of workers who entered the labor market between 1973 and 1990. These exclusions lead us to drop 133 observations. We exclude those who entered the labor market in earlier (pre-1973) years as cohort sizes are small (less than 20 per year). However, we have relaxed this assumption as a sensitivity check, and results are not appreciably

\footnotetext{
${ }^{17}$ Results are reported in Supplementary Appendix Table 3. We choose to not drop individuals who entered the labor market before 1979 as this would substantially reduce the number of observations in our analysis sample and, more importantly, the number of policy changes that we exploit to identify the effect of high cost mandates on health insurance and labor supply measures. See Table 1.
} 
different than those reported here. ${ }^{18}$ We exclude respondents who entered the labor market after $1990(n=81)$ as our policy data are only available through 1989 (Gruber 1994b), and in our regressions (detailed later) we lag mandates one year. ${ }^{19}$ Appendix Table A reports the number of respondents (unweighted and weighted) entering the labor market by year. The largest cohort was 1979 (unweighted $n=1,441$ ) and the smallest cohort was 1990 (unweighted $n=29$ ). ${ }^{20} 21$

Table 1 reports the effective date for each of the high cost mandates through 1989. By 1989, all states with the exception of Idaho and Wyoming had implemented at least one of these mandates. Three states (Kansas, Virginia, and Wisconsin) implemented all five mandates by 1989. Only states that implement high cost mandates during our study period contribute variation in our empirical models (differences-in-differences). We use bold text in Table 1 to indicate these changes. During our study period, 25 states implemented an alcohol treatment mandate, 15 states implemented an illicit drug treatment mandate, 11 states implemented a mental health treatment mandate, 27 states implemented a chiropractor mandate, and 30 states implemented a continuing coverage mandate. ${ }^{22}$ We take the unweighted count of the number of high cost mandates. This variable ranges from 0 to 5 .

\subsection{Control variables}

We include a set of pre-determined individual-level variables that are expected to predict the probability of an ESI offer, hourly wages, and labor supply in all regression models: race/ethnicity (African American and Hispanic, with White as the omitted group), age at labor market entrance, level of education at labor market entrance (high school, some college, and a college degree, with less than high school as the omitted category), a proxy for ability (age-

\footnotetext{
${ }^{18}$ Results are reported in Supplementary Appendix Table 4. Specifically, we included all respondents for whom we could locate a labor market entrance year and birth state, regardless of when they entered the labor market (with the exception of those leaving after 1990).

${ }^{19}$ Only 81 observations meeting other eligibility criteria for our sample that entered the labor market after 1990, suggesting that failure to include these observations might not lead to substantial bias in our estimates.

${ }^{20}$ We have estimated regressions dropping the school-leaving year 1973 from the analysis sample as ERISA became effective in 1974. Results are not appreciably different from those reported here. See Supplementary Appendix Table 5.

${ }^{21}$ We have explored the possibility that mandates influence the age at school-leaving. We find no evidence to support this hypothesis. Details available on request.

${ }^{22}$ In 1985 the federal government passed the Consolidated Omnibus Budget Reconciliation Act. This act became effective in April 1986 and mandated that a private insurance program give some employees the ability to continue health insurance coverage after leaving employment for a period up to 18 months. Therefore, this act superseded the state continuing coverage laws studied here, and these state laws may have little bite post-1986. To address this issue, we re-estimated our regression models excluding the continuing coverage mandate from our high cost mandate variable. More specifically, we construct our high cost mandate variable as the count of alcohol abuse treatment, illicit drug treatment, mental health treatment, and coverage of chiropractic services mandates only (this variable ranges from 0 to 4). Results, reported in Supplementary Appendix Table 6, are not appreciably different from those reported here.
} 
standardized Armed Forces Qualification Test [AFQT]), parental education as measured by mother's and father's years of education entered linearly and separately, rural residence at age 14, and indicators for access to cultural materials within the household at age 14 (library card, newspapers, and magazines). In addition, we include the number of years (entered linearly) between labor market entrance and the periods in which our outcome variable is measured. This variable is our proxy for potential experience in the labor market (Maclean 2013).

We include indicators for missing covariates and assign missing observations to the sample mean (continuous variable) or mode (binary variable) in our regression models. Results are robust if we instead drop all observations with missing covariate information. ${ }^{23}$

We also include labor market entrance state characteristics. Ideally, we would like to control for variables that influence both our outcomes and a state's propensity to pass the high cost mandates we study. We leverage information contained in the Annual Social and Economic Supplement to the CPS: unemployment rate, poverty rate, share of the population with some college education, average age, and the share of the population working for pay with a private employer. $^{24}$

\subsection{Empirical model}

Equation (1) presents the regression model we use to estimate the effects of high cost mandates at labor market entrance on ESI and labor market outcomes across the lifecycle: (1) $L_{i s t g}=\alpha_{0}+\alpha_{1} M_{s t}+\alpha_{2} E_{i g-t}+\alpha_{3} M_{s t} * E_{i g-t}+\alpha_{4}^{\prime} X_{i}+\alpha_{5}^{\prime} C_{s t}+G_{g}+S_{s}+D_{t}+\varepsilon_{i s t g}$ $L_{i s t g}$ is an outcome measured for individual $i$ in labor market entrance state $s$ and labor market entrance year $t$ measured in survey year $g . M_{s t}$ is the lagged number of high cost mandates in labor market entrance state $s$ and labor market entrance year $t .{ }^{25}$ This variable captures the contemporaneous effects of high cost mandates for new labor market entrants. $E_{i g-t}$ is potential labor market experience. $M_{s t} * E_{i g-t}$ is the interaction between the number of high cost mandates at labor market entrance and potential experience. Including this interaction term allows the effect of high cost mandates at labor market entrance to vary across time. For example, the effects (if present) may increase or decrease with time spent in the labor market.

\footnotetext{
${ }^{23}$ See Supplementary Appendix Table 7.

${ }^{24}$ In the years 1973 to 1976 the CPS did not separately identify all states; smaller states were suppressed due to confidentiality concerns (details available on request). We developed a crosswalk to create state-level characteristics for our analysis. Details are available on request and results are not appreciably different if we exclude these state-level controls from our regression models. However, we note that findings for ESI offers are more precisely estimated. See Supplementary Appendix Table 8.

${ }^{25}$ We re-estimated our model using the number of high cost mandates at labor market entrance (i.e., we did not lag the mandate variable). Results are not appreciably different. See Supplementary Appendix Table 9.
} 
This specification is in line with previous analyses within the career development literature (Kahn 2010, Maclean 2014, Altonji, Kahn, and Speer 2016)

$X_{i}$ is a vector of personal characteristics ${ }^{26}$ and $C_{s t}$ is a vector of labor market entrance state characteristics. $G_{g}$ includes survey year fixed effects. $S_{s}$ and $D_{t}$ are vectors of labor market entrance state and year fixed effects. Inclusion of the labor market entrance state fixed effects implies that we use within labor market entrance state variation in high cost mandates to identify effects. These fixed effects control for time invariant and difficult-to-observe (to the econometrician) between labor market entrance state differences that may be correlated with both the number of high cost mandates in the labor market entrance state and our outcomes. ${ }^{27}$

We utilize linear probability models (LPMs) for binary outcomes ${ }^{28}$ and OLS for continuous outcomes. We estimate separate models for men and women given established differences across sex in terms of labor market outcomes (Blau and Kahn 2007). We apply NLSY79 sample weights, but unweighted results are similar. ${ }^{29}$ Standard errors are clustered around the labor market entrance state.

The NLSY79 does not offer us sufficient information to determine whether a respondent's employer is compelled by passage of a high cost mandate to change insurance offerings to employees, wages, or labor demand; i.e., we cannot estimate the treatment on the treated (TOT). Instead, our estimates are intent-to-treat (ITT). We note our inability to estimate the TOT as a limitation of our study. We return to the ITT nature of our estimates after presenting our results.

\section{Results}

\subsection{Summary statistics}

Summary statistics are reported in Table 2. Male workers have slightly higher values for all our outcome variables than female workers, which is in line with higher labor market attachment among men than women. For instance, 79\% of male workers report an employer sponsored health insurance offer compared to $76 \%$ of female workers. In addition, men report

\footnotetext{
${ }^{26}$ These characteristics are time invariant. One may be concerned that including age at school-leaving, schoolleaving year, and potential experience may lead to collinearity issues. We re-estimated Equation (1) with no individual characteristics. Results are not appreciably different. However, we note that findings for ESI offers are more precisely estimated. See Supplementary Appendix Table 10.

${ }^{27}$ Results are not appreciably different if we instead include labor market entrance state-specific linear or quadratic time trends. Results are also robust to including state-of-residence at the time outcome variables are measured. See Supplementary Appendix Table 11.

${ }^{28}$ We choose the LPM over a probit or logit model as the LPM is not vulnerable to the incidental parameters problem (Greene 2004).

${ }^{29}$ See Supplementary Appendix Table 12.
} 
higher hourly wages (\$22.08 vs. \$16.68) and likelihood of working full-time (89.7\% vs. 72.4\%). The lagged mean number of high cost mandates in place at school-leaving is similar for both sexes. Demographics are also broadly similar for both men and women, and are comparable to an older sample such as the NLSY79. For example, the sample is less racially and ethnically diverse, and has lower educational attainment, relative to the current U.S. population.

\subsection{Life course effects of high costs mandates on ESI and labor market outcomes}

Table 3 reports estimates of the effect of high cost mandates at labor market entrance on ESI offers, wages, and labor supply. ${ }^{30}$

We find no statistically significant effect of high cost mandates on the probability that an employer offers health insurance to either men or women. However, male and female workers incur an initial wage penalty of $4 \%$ and $2.7 \%$, respectively, for each additional high cost mandate. While these effects dissipate with time in the labor market, they are observable for 12 years for both men and women after entering the job market. ${ }^{31}$ Passage of a high cost mandate leads to a reduction in the number of weeks worked among men but not women. More specifically, men who enter a labor market with an additional high cost mandate work 1.7\% fewer weeks per year than otherwise comparable men, and this disparity is observable for roughly 13 years. In terms of full-time employment, we find that entering a labor market with high cost mandates reduces the propensity of working full-time among both men and women, but these effects are not permanent. Indeed, an additional high cost mandate at labor market entrance reduces the probability of full-time work by 2.3 percentage points for both men $(2.5 \%)$ and women (3.2\%). These effects are observable for men approximately 13 years after labor market entrance. For women, the coefficient estimate on the interaction term is not precise, so we cannot rule out the absence of a persistent effect.

Our findings that wages and the probability of working full-time decrease in response to mandates can be interpreted in the context of our conceptual framework that workers place some value on these high cost mandates. The decline is also in line with Baicker and Chandra (2006), who find evidence that as health insurance costs increase, employers pass on the cost by decreasing wages and substitute part-time workers for full-time workers.

Interestingly, our findings for persistent effects of mandates are comparable to several studies that explore the career consequences of entering the labor market in a recession (i.e., a

\footnotetext{
${ }^{30}$ A full set of regression coefficient estimates is reported in Supplementary Appendix Tables 13A and 13B.

${ }^{31}$ We calculate the number of years at which the effects become zero by taking the derivative of Equation (1) with respect to $M_{s t}$, setting the derivative to zero, and solving for $E_{i g-t}$.
} 
reduction in aggregate demand). For example, Oreopoulos, von Wachter, and Heisz (2012) find that the wage effects of a 1 percentage point increase in the unemployment rate at labor market entrance are observable for up to 10 years among college educated Canadian men. Similarly, Kahn (2010), using a sample of college educated white men drawn from the NLSY79, shows that a 1 percentage point increase in the state unemployment rate at labor market entrance leads to lower wages that are apparent 15 years later. An exception is full-time work propensity among women, we are unable to rule out a permanent effect for this outcome.

\subsection{The importance of employer size at labor market entrance}

We next separately estimate Equation (1) for workers whose first job after school-leaving is with a small employer or with a large employer. We expect that the mandate effects will be stronger for those individuals who began their careers with small employers (Kaestner and Simon 2002). Although the previous literature has used contemporaneous employer size in analyses of mandate effects, because we are examining the importance of mandates at labor market entry we argue that it is the employer size at labor market entrance that is relevant here.

A limitation of the NLSY79 data is that employer size is not available between 1981 and 1985. These years are important as many workers in our sample entered the labor market in the early 1980s (see Appendix Table A). Moreover, we lack data on employer size before the NLSY79 survey commences, and many workers in our sample also entered the labor market in the 1970s (see Appendix Table A). Thus, this limitation of the NLSY79 prevents us from accurately identifying the sample of firms for whom the mandates may bind.

We use information on employer size available in 1979 to impute employer size in the first job for individuals who entered the labor market between 1973 and 1978. Thus, we implicitly assume that employer size remains constant across these years. Next, we use information on employer size in 1980 to impute employer size for the workers who entered the labor market between 1981 and $1985 .{ }^{32}$ For workers who entered the labor market in other years (i.e., 1979, 1980, and 1986-1990), we use the employer size information from the labor market entrance year. We stratify workers in the following manner: employer size at labor market entrance less than or equal to 100 workers vs. more than 100 workers.

This exercise potentially leads to a substantial degree of measurement error. Additionally, if employer size at labor market entrance is endogenous to the number of high cost mandates in place - for example, if mandates effect the propensity that a worker's first job is

\footnotetext{
${ }^{32}$ If employer size is missing in 1979 , we use the 1980 value (if non-missing) and vice-versa.
} 
with a small employer (Bailey and Webber 2016) — then we may be stratifying our sample on an endogenous variable, which can lead to bias. Moreover, we are unable to impute a firm size value at labor market entrance for all observations. Thus, the overall sample sizes (small firm workers and large firm workers) are smaller than the full sample. For these reasons, we interpret findings from this analysis cautiously and encourage readers to do the same.

Tables 4A and 4B report results for men and women, respectively. The findings for both are in line with the hypothesis that mandates should have larger effects among workers who start their careers working for smaller employers. Both men and women experience a wage penalty and are less likely to work full-time if they begin their careers with a small firm. We observe that, for men, there are wrong-signed (positive) coefficient estimates for the sample of workers who start careers with large employers.

\section{Robustness checks and extensions}

We next report results from several robustness checks to examine the stability of our findings to different modeling approaches. We also explore extensions to the main model.

\subsection{CPS replication}

We replicate our NLSY79 analysis in the Annual Social and Economic Supplement (ASEC) to the CPS. We chose to replicate our analysis in the CPS given that it is a commonly utilized dataset to study state mandate effects. Moreover, the CPS has the advantage of being representative at the state and national (vs. only national) level; we are somewhat concerned that smaller states (e.g., Wyoming) may have limited coverage in the NLSY79. To this end, we use CPS data available through the Integrated Public Use Microdata Series project (Flood et al. 2017). We draw data from the 1976 to 2013 CPS surveys and focus on individuals 18 to 54 years, the same age range we examine in our study and in previous investigations of mandate effects (Kaestner and Simon 2002). ${ }^{33}$

\footnotetext{
${ }^{33}$ We continue to view the NLSY79 as more useful than the CPS for our purposes as we can (i) accurately measure labor market entrance, (ii) track the same workers over the life course, and (iii) examine employer offers of health insurance rather than take up of employer-sponsored health insurance. Moreover, the CPS did not regularly collect reported hourly wage until 1989, after the majority of mandates we study were already in place (Table 1). Thus, as outlined later in the manuscript, we construct wages using annual wage income, weeks worked in the past year, and usual hours worked per week. Constructing wages in this manner likely leads to measurement error in our wage variable. To dig deeper into this issue, we have compared reported hourly wages and constructed hourly wages over the period 1989 to 2013 in the ASEC within the sample of workers for which we have both wage variables. We apply the same outlier-corrections as we apply in the analysis (excluding hourly wages less than $\$ 1$ and greater than \$1,000). We also apply weights for the ASEC sample. Mean (median) inflation-adjusted constructed hourly wage is $\$ 16.84$ (\$13.95) and mean (median) inflation-adjusted reported hour wage is $\$ 15.56$ (\$13.17). These values are similar, but not identical. We note our use of constructed wages in the CPS as a limitation of the study. Further, we argue that, for a study of persistent wage effects over our study period, the NLSY79 is a more suitable dataset given that this dataset includes reported hourly wages.
} 
We truncate the CPS study period in 2013 as, after this point, there were substantial changes to the insurance and income questions, both of which we leverage in our replication. We use CPS variables that pertain to the last calendar year (we call this the "income year"), thus our study period is 1975 to 2012 . We are unable to use earlier years of the CPS as some of our outcome variables are not available until 1976. ${ }^{34}$ We do not have the year of labor market entrance in the CPS and instead must impute this information. We assign the labor market entrance year using the following formula: income year - age $+6+$ years of completed schooling at the time of the survey. ${ }^{35}$ Hence, we assume that the years of schooling reported at the time of the CPS survey accurately captures completed schooling at labor market entrance. If individuals return to school after labor market entrance, this behavior will lead to measurement error. Potential experience is measured as the difference between the income year and the imputed year of labor market entrance.

We estimate the following regression model in the CPS:

(2) $L M_{i s t g}=\beta_{0}+\beta_{1} M_{s t}+\beta_{2} M_{s t} * E_{i g-t}+\beta_{3}^{\prime} X_{i}+\beta_{4}^{\prime} C_{s t}+S_{s}+G_{g}+\mu_{i s t g}$

Thus, this regression model is similar to Equation (1). ${ }^{36}$ Given near perfect collinearity we control for age and not potential experience in Equation (2); however, we do control for the interaction between the number of high cost mandates at labor market entrance and potential experience. ${ }^{37}$ Moreover, we use current state to proxy for the labor market entrance state. ${ }^{38}$ Our outcome variables closely match our NLSY79 outcomes and pertain to the income year: holding ESI (0/1), ${ }^{39}$ the logarithm of the hourly wage, ${ }^{40}$ the logarithm of weeks worked, and

\footnotetext{
${ }^{34}$ Specifically, the CPS underwent a major redesign between 1975 and 1976. Based on our analysis of the CPS data, our measures of wages and labor supply cannot be easily compared before and after this change. Our measure of ESI is only available in the CPS from 1980 onward as this is the year in which the question was first asked to ASEC CPS respondents.

${ }^{35}$ As an example, a respondent who is 25 years in CPS income year 2000 with high school education would be computed as entering the labor market in 1993 at age 18. If the same person has college-level education, their estimate job market entrance year would be 1997 at age 22. This approach is similar to the method employed by Genda, Kondo, and Ohta (2010) in their analysis of the persistent effects of entering the labor market in a recession. ${ }^{36}$ This regression model is also similar to studies that explore the contemporaneous effects of health insurance mandates on ESI and labor market outcomes. For example, Gruber (1994b) and Kaestner and Simon (2002).

${ }^{37}$ We derive our labor market entrance state characteristics using the CPS. Thus, where relevant, to construct the state-level CPS variables we exclude the respondent to avoid peer effects concerns. See Angrist and Pischke (2009) for a discussion of this issue. Details available on request.

${ }^{38}$ The CPS has less detailed information on respondent personal characteristics than the NLSY79. Thus, we cannot include all controls that we include in Equation (1). Instead, we control for current age, race/ethnicity, and education. However, as noted earlier in the manuscript, removing individual-level controls from Equation (1) does not lead to appreciably different findings. Due to the manner in which we assign labor market entrance, we are unable to control for both labor market entrance year fixed effects and income year fixed effects.

${ }^{39}$ We cannot separate ESI offers from ESI take-up as we can in the NLSY79.

${ }^{40}$ As we do in the NLSY79 analyses, we drop outlier wages: hourly wages less than $\$ 1$ and greater than $\$ 1000$.
} 
full-time work (working 35 hours per week or more; 0/1). We apply ASEC sample weights ${ }^{41}$ and cluster standard errors around the state. Results are reported in Appendix Table B1.

Our CPS findings confirm our NLSY79 findings: those individuals who enter labor markets characterized by a higher number of mandates have lower wages, work fewer weeks per year, and are less likely to work full-time than comparable workers, but mandate effects dissipate with time in the labor market. Interestingly, we find statistically significant evidence that high cost mandates do reduce the probability that a worker holds ESI, but this effect dissipates with time in the labor market. In line with previous literature, we have also excluded non-private firm workers and the self-employed in unreported analyses to focus on samples of workers most likely to be affected by the mandates (Kaestner and Simon 2002). Results, reported in Appendix Table B2, are not appreciably different after making these exclusions.

It may be worthwhile to consider why we identify ESI take up and labor market effects, while some other studies (see Section 2.1), using similar data and research designs, have reached different (often null) conclusions. We suspect that our focus on an earlier time period (our health insurance mandate data cover the period 1975 to 1989) is a potential explanation (most studies that leverage the CPS consider data from the 1980s and onward). State mandates may have been more binding in the 1970s than they have in more recent periods (National Council of State Legislatures 2017). That is, employers did not voluntarily choose to cover such benefits prior to state regulations. Moreover, we focus on high cost mandates rather than overall counts of mandates, and the latter parametrization may dilute high cost mandate effects. Mandates may have been binding for a majority of employers as self-insurance among firms was less common in the earlier years we study here. For example, only 8\% of firms were self-insured in 1984 (McDonnell et al. 1986); this estimate reflects firm self-insurance status during the second half of our study period and the rate was plausibly lower during earlier years of this period. We also focus on labor market entrants rather than a general sample of workers, employers may find it more feasible to adjust compensation (wage and non-wage) for labor market entrants vs. more experienced or incumbent workers.

In addition, our ESI effects differ across the NLSY79 and the CPS. The NLSY79 measures the probability of having an ESI offer whereas the CPS measures the probability of holding ESI; the latter confounds offers and take-up decisions. The findings from the NLSY79 and the CPS are in line with the hypothesis that mandates have no significant effect on an

${ }^{41}$ Unweighted results are very similar. See Supplementary Appendix Table 14. 
employer's decision to offer ESI but decrease the likelihood of holding ESI if employers pass on mandate cost to workers by charging higher premiums and imposing substantial cost-sharing requirements (Abraham and Feldman 2010, Cooper and Vistnes 2003). In addition, our sample spans the 1980s and 1990s, when public health insurance crowded out private health insurance (Cutler and Gruber 1996, Gruber and Simon 2008) so individuals with ESI offer may have chosen to take up public insurance instead.

\subsection{Accounting for differences in mandate costs}

In the main analyses we use an unweighted count of the number of high cost mandates in the state/year of labor market entrance. However, it is plausible that the five mandates we study impose different costs on employers and/or are differently valued by workers. To explore this possibility, we follow a weighting scheme developed by Gruber (1994b) to account for differences in mandate cost (Gruber's weighting scheme, based on his analysis of the specific mandate costs, upweights more costly mandates and downweights less costly mandates). We construct the weighted number of mandates in the state/year of labor market entrance with the following equation:

$$
W_{\text {st }}=\text { Alcohol }_{s t}+\text { Drug }_{s t}+5 * \text { Mental }_{s t}+1.5 * \text { Chiropractor }_{\text {st }}+3 * \text { Con }_{\text {Cov }} \text { st }
$$

where Alcohol $_{s t}$, Drug $_{s t}$, Mental $_{s t}$, Chiropractor $_{\text {st }}$, and Con Cov st are alcohol treatment, illicit drug treatment, mental health treatment, access to a chiropractor, and continuing coverage mandates, respectively. Thus, this variable upweights mental health treatment, chiropractor, and continuing coverage mandates relative to alcohol treatment and illicit drug treatment mandates to account for differences in costs. As noted by Gruber, this weighting scheme will lead to biased estimates if the costs and hence the weights changes with time. Given that we study a somewhat earlier period (1973 to 1990) than Gruber (1979, 1983, and 1989), this potential bias is of concern for our study and hence we interpret the results cautiously. Results are reported in Appendix Table $\mathrm{C}$ and are broadly similar to those generated in Equation (1), which equally weights the mandates we study. It is important to note that for all estimates, the confidence interval with and without weighted mandates overlap; hence, while we note that the specific point estimates and associated standard error estimates differ across the two specifications, we cannot reject the hypothesis that the estimates are equal.

\subsection{Worker skill}

We next estimate separate regressions for workers of different skill levels. We focus on workers who left school with a high school diploma or less ("lesser skill workers") and some 
college education ("higher skill workers"). ${ }^{42}$ Ex ante, it is not clear whether we should expect stronger mandate effects for lesser or higher skill workers. On the one hand, higher skill workers have higher human capital investment, and thus adverse labor demand shocks may have larger implications for their life course employment outcomes. Alternatively, lesser skill workers may work for employers who are more likely to pass on labor costs to employees. In general, lesser skill workers are more adversely affected during recessions (a reduction in aggregate demand) than higher skill workers, suggesting that they are more vulnerable to negative contemporaneous labor demand shocks than higher skill workers (Hoynes, Miller, and Schaller 2012). Finally, Buchmueller, DiNardo, and Valletta (2011) note that theory suggests that the effects of a mandate should be largest for workers who place a low value on health insurance and thus have lower rates of ESI in the absence of a mandate; in particular, such workers are likely to be of lower skill.

Appendix Tables D1 and D2 present estimates by skill level at school-leaving for the male and female samples. Our findings suggest that lesser skill workers, especially those who are male, disproportionately bear the incidence of mandate costs: coefficient estimates are generally larger and more precisely estimated in the sample of lesser skill workers.

\subsection{Unionization}

We also explore heterogeneity across union status at school-leaving. Institutional restrictions such as union rules limit the ability of firms to pass on all benefit costs to workers (Baicker and Chandra 2006). We hypothesize that unionized jobs may offer some protections against the negative effects of private health insurance mandates on labor market outcomes. Information on union status is collected in all years of the NLSY79, but we do not have information on union status in years before 1979. Thus, similar to our firm size variable, we assign the 1979 value to school-leaving years 1973 to 1978 (see Section 5.3). Appendix Tables $\mathrm{E} 1$ and $\mathrm{E} 2$ report results by unionization.

We find that workers whose first jobs are unionized are potentially less affected by high cost mandates than those workers whose first jobs are non-unionized. These findings suggest that the wages and hours of unionized workers may be protected from market factors such as the health insurance mandates we study. These results are in line with Lubotsky and Olson (2015) whose study on teachers, a group of workers that is typically unionized, finds that employers do

\footnotetext{
${ }^{42}$ Specifically, we classify those workers who entered the labor market with 12 years or less as "lesser skill workers" and those workers who entered the labor market with some college (but less than a college degree), a college degree, or a graduate degree as "high skill workers."
} 
not adjust wages and hours in response to increasing healthcare costs. We cannot discriminate between this hypothesis and the hypothesis that unionized workers are more likely to work for self-insured employers who are not bound by ERISA (Acs et al. 1996). However, given the low level of self-insurance during our study period, $8 \%$ of firms were self-insured (McDonnell et al. 1986), we suspect that differences in the propensity to self-insurance between unionized and non-unionized firms cannot fully explain differences in the estimates across these two groups.

\subsection{Heterogeneity across mandates}

We also estimate Equation (1) entering one mandate at a time into the regression model. The purpose of this exercise is to assess whether there are differences in the relationship between the mandates and our outcomes. Results are reported in Appendix Tables F1 to F5. We chose not to include all mandates in the same regression as collinearity between the mandates may impede our ability to precisely estimate treatment effects (Gruber 1994b, Meer and West 2011). We find that there is heterogeneity in the relationship between the mandates that we study here and our outcomes. For example, when we use the count of high cost mandates in our key specification, we find no statistically significant evidence that mandates effect the probability that a worker receives an offer of health insurance from his employer or the number of weeks worked in the past year. However, when we study the mandates separately we find suggestive evidence that chiropractor mandates reduce the probability that a worker is offered ESI. Moreover, the wage effects we identify in our main findings appear to be driven by alcohol treatment and continuing coverage mandates.

We suspect that differences across mandates in terms of employer costs and/or employee valuation of the mandated benefit may drive differences in treatment effects. Additionally, the variation we use for identification for each specific mandate is driven by a different set of states (see Table 1). Finally, omitted variable bias may also lead to differences.

\subsection{Contemporaneous mandates as an additional control variable}

One concern with our analysis thus far is that we do not control for contemporaneous high cost mandates in the regression model, and that failure to include this variable may lead us to falsely attribute the effect of contemporaneous mandates to mandates at labor market entrance. To explore this possibility, we next re-estimate our core regression model including contemporaneous mandates as an additional control variable. ${ }^{43}$ Results are reported in

\footnotetext{
43 To construct our contemporaneous mandates, we used information contained in multiple industry documents (e.g., Blue Cross Blue Shield annual reports) to capture mandate changes post-1989 (the last year for which we have mandate data from Gruber (1994b)). There are some discrepancies across the various sources; thus, we chose
} 
Appendix Table G and are nearly identical to our core findings. The similarity of the results suggests that our failure to include contemporaneous mandates does not lead to substantial bias.

\subsection{Alternative specification for mandate dynamics}

We next estimate a model that allows for a more flexible relationship between the number of high cost mandates at labor market entrance and potential experience. To this end, we interact the high cost mandates variable with indicators for 1 to 10,11 to 20 , and 21 or more years of potential labor market experience. We report results generated in this specification in Appendix Tables H1 and H2. Overall, these results are in line with our main findings but are generally imprecise. We suspect that the lack of precision may be due to somewhat small labor market entrance state cell sizes in the experience categories. The results, however, conform with our broad finding that workers who enter a highly regulated market (in terms of private health insurance) have lower wages, work fewer weeks per year, and are less likely to work full-time than comparable workers who enter a less regulated labor market. We find no evidence that the mandated benefits we study affect the propensity of employers to offer insurance to employees. Interestingly, we find some evidence that, among men only, wages (while they are initially lower) appear to rebound 11 to 20 years after labor market entrance.

\section{Discussion}

The debate over the relative merits and demerits of mandated benefits on access to equitable and affordable health insurance and labor market outcomes is both long-standing and contentious. While we do not propose that our study can provide consensus on the broader welfare effects of mandated benefits, we are able to offer new insight on mandate effects. Specifically, we are the first study to explore the persistent effects of high cost mandates on new labor market entrants' access to ESI, wages, and labor supply.

Three central findings emerge from our analysis. First, mandates at labor market entrance reduce wages and labor supply as measured by weeks worked and the probability of holding a full-time job. Second, mandate effects are persistent but not permanent, as they generally dissipate with time spent in the labor market. Third, the findings are concentrated among lesser skill workers and workers who began their career with small (less than 100 workers) and non-unionized employers. Thus, while the previous literature on health insurance mandates, and mandated benefits more broadly, has focused on contemporaneous effects, we document that these mandates lead to persistent distortions in labor market outcomes. 
Our results have an intent-to-treat (ITT), and not a treatment on the treated (TOT), interpretation. Thus, it is important to think through whether or not our estimated ITT effect sizes are reasonable. To the best of our knowledge, there is no standard manner in which to address this question. We therefore turn to several lines of related evidence and attempt to compare our estimates with benchmarks derived from other studies to put our estimates in perspective. First, Gruber (1994b) shows that the mandates we study increased premiums by $12 \%$ and accounted for $50 \%$ of overall mandated benefit costs during the $1970 \mathrm{~s}$ and $1980 \mathrm{~s}$. Hence, these mandates were costly to employers and most likely relevant during our study period. Second, Jensen and Morrisey (1999) state that passage of a state mandated benefit law affects $33 \%$ to $42 \%$ of the population using data from 1995 . Because we use mandated benefit data from an earlier period when self-insurance by firms - a key factor that may mute the scope of state mandates - was lower, we argue that share of the population that was affected during our study period (1973 and 1990) was potentially above the range established by Jensen and Morrisey (1999). Third, there is evidence that state mandates specifically and employer healthcare costs generally influence the outcomes that we study (see Section 2). Our main point estimates (reported in Table 3 ) imply a $1.7 \%$ to $4.0 \%$ and $2.3 \%$ to $3.2 \%$ contemporaneous reduction in the outcomes we study among men and women respectively (we note that not all estimates are precise and only consider statistically significant effects in this discussion). Examination of the upper tail of the $95 \%$ confidence intervals surrounding these point estimates suggests that we cannot rule out effect sizes as small as $-1 \%$ to $-0.05 \%$. Overall, we argue that these statistics imply that our estimated ITT effect sizes are not outrageously large.

Our study, while novel, is not without limitations. First, we focus on older cohorts of workers and five specific health insurance mandates. Therefore, the generalizability of our findings to different cohorts and mandates is not clear. Second, we lack information on the generosity of ESI held by respondents. For instance, employers can pass on the cost of mandates by increasing premiums and or copays, or by offering insurance coverage that is less generous along other dimensions (Bailey 2014). Our research is silent on this possible channel of adjustment, although our analysis of the Current Population Survey is suggestive that employers may leverage this margin to pass on higher healthcare costs to employees. Third, the NLSY79 is representative at the national, not state, level and hence some of the labor market entrance state-year cells are small. We note, however, that we are able to replicate our labor market results from the NLSY in the CPS, which has sizable state-year cells. 
Our findings may be useful for thinking through health policy recommendations that extend employers' responsibility for health insurance. Our estimates suggest that any law that increases the cost of health insurance for employers may lead to distortions of wages and labor supply, and that these distortions will be experienced by current workers as well as those entering the labor market. It is not clear whether workers' trade-offs between generous health insurance, wages, and labor supply are welfare-enhancing. At a minimum, policy makers should consider the downstream and perhaps unintended consequences of these regulations.

While state mandates arguably have less "bite" in current U.S. labor markets than in the historical labor markets of the 1970s and 1980s that we study, our findings are nevertheless important for understanding how healthcare costs may affect employer-sponsored health insurance, wage compensation, and labor demand for more recent cohorts. In particular, between 2012 and 2017 the average total cost of an employer-sponsored family insurance plan rose from $\$ 15,745$ to $\$ 18,764$, a $19 \%$ increase (Claxton et al. 2017). Employer contributions increased by $14.2 \%$ over this period, and employee contributions increased by $27 \%$ while earnings increased just $12 \%$. Collectively, these findings suggest that healthcare costs are high and rising for both employers and employees, and employees are shouldering a larger share of this burden overtime with earnings that are not commensurately increasing. Extrapolating from our findings for mandates, which increase healthcare costs, suggests that workers who enter labor markets with high healthcare costs may persistently experience lower wages and labor demand by employers to offset healthcare costs. 
Table 1. State private health insurance high cost mandate effective dates

\begin{tabular}{|c|c|c|c|c|c|}
\hline State & $\begin{array}{c}\text { Alcohol } \\
\text { treatment } \\
\text { mandate }\end{array}$ & $\begin{array}{c}\text { Illicit } \\
\text { drug treatment } \\
\text { mandate }\end{array}$ & $\begin{array}{c}\text { Mental } \\
\text { health treatment } \\
\text { mandate }\end{array}$ & $\begin{array}{l}\text { Chiropractor } \\
\text { mandate }\end{array}$ & $\begin{array}{c}\text { Continuing } \\
\text { coverage } \\
\text { mandate }\end{array}$ \\
\hline AK & 1989 & 1989 & & & \\
\hline $\mathrm{AL}$ & & & & 1984 & \\
\hline AR & & & & 1975 & \\
\hline $\mathrm{AZ}$ & & & & 1971 & 1979 \\
\hline CA & & & 1976 & 1983 & \\
\hline $\mathrm{CO}$ & & & 1971 & 1969 & 1985 \\
\hline CT & 1977 & & & 1975 & 1986 \\
\hline DE & & & & 1989 & 1975 \\
\hline FL & & & & 1963 & \\
\hline GA & & & & 1974 & \\
\hline IA & & & & 1980 & 1986 \\
\hline ID & & & & & 1984 \\
\hline IL & 1972 & & & & \\
\hline IN & & & 1978 & 1969 & 1984 \\
\hline KS & 1978 & 1978 & & 1974 & \\
\hline KY & & & & 1973 & 1978 \\
\hline LA & & & 1976 & 1986 & 1980 \\
\hline MA & 1976 & & 1973 & 1975 & \\
\hline MD & 1981 & 1979 & 1984 & 1985 & 1977 \\
\hline ME & 1984 & 1984 & & 1974 & 1983 \\
\hline MI & 1982 & 1982 & & 1981 & \\
\hline $\mathrm{MN}$ & 1978 & 1978 & & 1968 & \\
\hline MO & 1977 & & & 1973 & 1974 \\
\hline MS & 1975 & & 1984 & 1976 & 1985 \\
\hline MT & 1984 & 1984 & & 1980 & \\
\hline $\mathrm{NC}$ & & & 1985 & 1967 & \\
\hline ND & 1985 & 1985 & & 1977 & 1982 \\
\hline $\mathrm{NE}$ & & & 1976 & & 1983 \\
\hline NH & & & & 1975 & 1981 \\
\hline NJ & 1977 & & & 1969 & 1981 \\
\hline NM & & & & & \\
\hline NV & 1985 & 1985 & & 1973 & 1983 \\
\hline NY & 1981 & 1988 & 1979 & 1975 & 1988 \\
\hline $\mathrm{OH}$ & 1979 & & & 1973 & \\
\hline $\mathrm{OK}$ & & & 1984 & 1969 & 1984 \\
\hline OR & 1984 & 1984 & & 1971 & 1976 \\
\hline PA & 1986 & & & & 1981 \\
\hline RI & 1980 & 1988 & & 1971 & \\
\hline $\mathrm{SC}$ & & & & 1968 & 1977 \\
\hline SD & & & & & 1979 \\
\hline TN & & & & 1970 & 1984 \\
\hline $\mathrm{TX}$ & 1986 & 1990 & & 1981 & 1981 \\
\hline UT & & & 1977 & 1977 & 1986 \\
\hline VA & 1978 & 1978 & & 1975 & 1986 \\
\hline VT & 1986 & & & 1973 & 1986 \\
\hline WA & 1975 & 1975 & 1971 & & \\
\hline WI & 1975 & 1975 & & 1971 & \\
\hline WY & & & & 1988 & 1980 \\
\hline
\end{tabular}

Notes: Bold text indicates changes that occur during study period 1972 to 1989 (mandates are lagged one year in regression models). Data source: Gruber (1994b). 
Table 2. Summary statistics: NLSY79 1979-2012

\begin{tabular}{lcc}
\hline \hline Sample: & Men & Women \\
\hline Outcome Variables & & \\
\hline ESI $\dagger$ & 0.790 & 0.761 \\
Hourly wage & 22.08 & 16.68 \\
Weeks worked, past year & 46.11 & 43.95 \\
Work full-time, past year & 0.897 & 0.724 \\
\hline Private health insurance mandates & 1.439 & \\
\hline Lagged high cost mandates at labor market entrance & & 1.414 \\
\hline Demographics & 18.78 \\
\hline Age at labor market entrance & 0.818 & 18.60 \\
White & 0.129 & 0.817 \\
African American & 0.052 & 0.132 \\
Hispanic & 0.177 & 0.051 \\
Less than high school at labor market entrance & 0.493 & 0.132 \\
High school at labor market entrance & 0.149 & 0.493 \\
Some college at labor market entrance & 0.181 & 0.192 \\
College degree at labor market entrance & -0.038 & 0.183 \\
Age-adjusted AFQT score & 11.72 & -0.037 \\
Mother's education & 11.90 & 11.63 \\
Father's education & 0.232 & 11.76 \\
Rural residence at age 14 & 0.768 & 0.226 \\
Live with both biological parents at age 14 & 0.739 & 0.757 \\
Library card in the home at age 14 & 0.679 & 0.784 \\
Magazines in the home at age 14 & 0.854 & 0.670 \\
Newspapers in the home at age 14 & 1979.9 & 0.840 \\
Labor market entrance year & 1992.7 & 1979.7 \\
Survey year & & 1992.8 \\
\hline Labor market entrance state level characteristics & 0.048 & \\
\hline Unemployment rate & 0.124 & 0.048 \\
Poverty rate & 0.282 & 0.125 \\
Some college education rate & 33.17 & 0.280 \\
Age & 0.751 & 33.14 \\
Private wage-earning worker rate & 85,616 & 0.750 \\
\hline Unweighted observations & $0 f 911$ \\
\hline Notes: Samp incles obser & & \\
\hline
\end{tabular}

Notes: Sample includes observations that provide a valid response to one of the four outcome variables, thus this sample departs from the sample sizes in the regression tables. NLSY79 weights applied.

${ }^{\dagger} \mathrm{ESI}=$ Employer-sponsored health insurance offer. 
Table 3. The persistent effect of high cost mandates at labor market entrance on ESI access and labor market outcomes: NLSY79 1979-2012

\begin{tabular}{lcccc}
\hline \hline Outcome: & ESI $^{\mathbf{1}}$ & Log(wages) & Log(weeks) & Full-time \\
\hline Male sample & & & & \\
\hline Sample proportion/mean & 0.790 & 22.08 & 46.11 & 0.897 \\
\hline High cost mandates & -0.0133 & $-0.0399^{* *}$ & $-0.0165^{* *}$ & $-0.0226^{* * *}$ \\
& $(0.0080)$ & $(0.0154)$ & $(0.0081)$ & $(0.0054)$ \\
High cost mandates $\times$ & 0.0005 & $0.0032^{* * *}$ & $0.0013^{* * *}$ & $0.0018^{* * *}$ \\
potential experience & $(0.0003)$ & $(0.0008)$ & $(0.0004)$ & $(0.0003)$ \\
\hline Unweighted observations & 68,464 & 79,806 & 83,489 & 82,179 \\
\hline Female sample & & & & \\
\hline Sample proportion/mean & 0.761 & 16.68 & 43.95 & 0.724 \\
\hline High cost mandates & -0.0122 & $-0.0272^{* * *}$ & 0.0027 & $-0.0234^{* * *}$ \\
& $(0.0074)$ & $(0.0089)$ & $(0.0088)$ & $(0.0075)$ \\
High cost mandates $\times$ & 0.0005 & $0.0022^{* * *}$ & -0.0004 & 0.0007 \\
potential experience & $(0.0004)$ & $(0.0005)$ & $(0.0003)$ & $(0.0004)$ \\
\hline Unweighted observations & 64,163 & 76,596 & 80,012 & 78,855 \\
\hline Notes:All
\end{tabular}

Notes: All models estimated with least squares (continuous variables) or a linear probability model (binary variables), and control for demographics, labor market entrance state fixed effects, and labor market entrance year fixed effects. NLSY79 sample weights applied. Standard errors are clustered around the labor market entrance state and reported in parentheses.

${ }^{1}$ ESI=Employer-sponsored health insurance offer.

$* * * * * ; *=$ statistically different from zero at the $1 \% ; 5 \% ; 10 \%$ level. 
Table 4A. The persistent effect of high cost mandates at labor market entrance on ESI access and labor market outcomes by employer size at labor market entrance: NLSY79 men 1979-2012

\begin{tabular}{lcccc}
\hline Outcome: & ESI $^{\mathbf{1}}$ & Log(wages) & Log(weeks) & Full-time \\
\hline$\leq 100$ employees & & & & \\
\hline Sample proportion/mean & 0.798 & 22.92 & 47.43 & 0.905 \\
\hline High cost mandates & -0.0210 & $-0.0670^{* * *}$ & $-0.0174^{*}$ & $-0.0340^{* * *}$ \\
& $(0.0125)$ & $(0.0229)$ & $(0.0098)$ & $(0.0078)$ \\
High cost mandates $\times$ & 0.0008 & $0.0038^{* * *}$ & $0.0012^{* * *}$ & $0.0023^{* * *}$ \\
potential experience & $(0.0005)$ & $(0.0009)$ & $(0.0003)$ & $(0.0004)$ \\
\hline Unweighted observations & 25,192 & 29,116 & 30,274 & 29,800 \\
\hline$>100$ employees & & & & \\
\hline Sample proportion/mean & 0.864 & 23.49 & 47.54 & 0.940 \\
\hline High cost mandates & 0.0076 & -0.0010 & $0.0483^{* * *}$ & 0.0018 \\
& $(0.0197)$ & $(0.0412)$ & $(0.0145)$ & $0.0160)$ \\
High cost mandates $\times$ & 0.0014 & $0.0035^{* *}$ & 0.0001 & $0.0012^{*}$ \\
potential experience & $(0.0009)$ & $(0.0016)$ & $(0.0004)$ & $(0.0006)$ \\
\hline Unweighted observations & 7,124 & 7,867 & 8,086 & 7,988 \\
\hline Note & & &
\end{tabular}

Notes: All models estimated with least squares (continuous variables) or a linear probability model (binary variables), and control for demographics, labor market entrance state fixed effects, and labor market entrance year fixed effects. NLSY79 sample weights applied. Standard errors are clustered around the labor market entrance state and reported in parentheses. The sum of the $\leq 100$ employees and $>100$ employees sample is smaller than the full sample reported in Table 3 due to a substantial amount of missing information. See the text associated with this table for more details.

$* * * ; * * ; *=$ statistically different from zero at the $1 \% ; 5 \% ; 10 \%$ level.

${ }^{1} \mathrm{ESI}=$ Employer-sponsored health insurance offer. 
Table 4B. The persistent effect of high cost mandates at labor market entrance on ESI access and labor market outcomes by employer size at labor market entrance: NLSY79 women 1979-2012

\begin{tabular}{lcccc}
\hline Outcome: & ESI $^{\mathbf{1}}$ & Log(wages) & Log(weeks) & Full-time \\
\hline$\leq 100$ employees & & & & \\
\hline Sample proportion/mean & 0.759 & 17.07 & 45.05 & 0.718 \\
\hline High cost mandates & -0.0142 & $-0.0456^{* *}$ & -0.0048 & $-0.0374^{* * *}$ \\
& $(0.0147)$ & $(0.0222)$ & $(0.0170)$ & $(0.0110)$ \\
High cost mandates $\times$ & -0.0001 & $0.0023^{* * *}$ & -0.0002 & 0.0008 \\
potential experience & $(0.0006)$ & $(0.0008)$ & $(0.0005)$ & $(0.0006)$ \\
\hline Unweighted observations & 20,006 & 23,880 & 24,773 & 24,408 \\
\hline$>100$ employees & & & & \\
\hline Sample proportion/mean & 0.835 & 19.06 & 46.62 & 0.765 \\
\hline High cost mandates & -0.0027 & -0.0397 & -0.0023 & -0.0361 \\
& $(0.0219)$ & $(0.0420)$ & $(0.0198)$ & $0.0245)$ \\
High cost mandates $\times$ & 0.0007 & $0.0046^{* * *}$ & 0.0001 & 0.0010 \\
potential experience & $(0.0009)$ & $(0.0013)$ & $(0.0006)$ & $(0.0010)$ \\
\hline Unweighted observations & 7,220 & 8,293 & 8,583 & 8,455 \\
\hline
\end{tabular}

Notes: All models estimated with least squares (continuous variables) or a linear probability model (binary variables), and control for demographics, labor market entrance state fixed effects, and labor market entrance year fixed effects. NLSY79 sample weights applied. Standard errors are clustered around the labor market entrance state and reported in parentheses. The sum of the $\leq 100$ employees and $>100$ employees sample is smaller than the full sample reported in Table 3 due to a substantial amount of missing information. See the text associated with this table for more details.

$* * * ; * ; *=$ statistically different from zero at the $1 \% ; 5 \% ; 10 \%$ level.

${ }^{1} \mathrm{ESI}=$ Employer-sponsored health insurance offer. 
Appendix Table A. Labor market entrance cohort size: NLSY79 1979-2012

\begin{tabular}{l|c|c}
\hline $\begin{array}{l}\text { Labor market } \\
\text { entrance year }\end{array}$ & $\begin{array}{c}\text { Number of labor market } \\
\text { Entrants (unweighted) }\end{array}$ & $\begin{array}{c}\text { Total number of labor market } \\
\text { entrants (weighted) }\end{array}$ \\
\hline 1973 & 88 & 181,518 \\
1974 & 165 & 403,624 \\
1975 & 601 & $1,519,011$ \\
1976 & 988 & $2,410,380$ \\
1977 & 1,164 & $2,817,389$ \\
1978 & 1,423 & $3,572,607$ \\
1979 & 1,441 & $3,809,763$ \\
1980 & 1,189 & $3,134,488$ \\
1981 & 1,136 & $3,209,784$ \\
1982 & 1,023 & $3,077,539$ \\
1983 & 632 & $2,009,049$ \\
1984 & 404 & $1,309,966$ \\
1985 & 270 & 922,537 \\
1986 & 203 & 802,908 \\
1987 & 123 & 405,266 \\
1988 & 76 & 250,557 \\
1989 & 58 & 174,093 \\
1990 & 29 & 9,5623 \\
\hline Total & 11,013 & $30,106,099$ \\
\hline
\end{tabular}

Notes: One observation per respondent that has a valid response to at least one of the outcome variables. 
Appendix Table B1. The persistent effect of high cost mandates at labor market entrance on ESI and labor market outcomes: Current Population Survey 1976-2013

\begin{tabular}{|c|c|c|c|c|}
\hline Outcome: & ESI $^{1}$ & Log(wages) & Log(weeks) & Full-time \\
\hline \multicolumn{5}{|l|}{ Men } \\
\hline Sample proportion/mean & 0.770 & 17.99 & 44.61 & 0.864 \\
\hline High cost mandates & $\begin{array}{c}-0.0298 * * * \\
(0.0042)\end{array}$ & $\begin{array}{c}-0.0521 * * * \\
(0.0066)\end{array}$ & $\begin{array}{c}-0.0379 * * * \\
(0.0091)\end{array}$ & $\begin{array}{c}-0.0331 * * * \\
(0.0045)\end{array}$ \\
\hline $\begin{array}{l}\text { High cost mandates } \times \\
\text { potential experience }\end{array}$ & $\begin{array}{c}0.0025 * * * \\
(0.0003)\end{array}$ & $\begin{array}{c}0.0046 * * * \\
(0.0005)\end{array}$ & $\begin{array}{c}0.0034 * * * \\
(0.0004)\end{array}$ & $\begin{array}{c}0.0031 * * * \\
(0.0004)\end{array}$ \\
\hline Unweighted observations & 22,2603 & 310,973 & 332,131 & 332,131 \\
\hline \multicolumn{5}{|l|}{ Women } \\
\hline Sample proportion/mean & 0.721 & 14.37 & 42.24 & 0.713 \\
\hline High cost mandates & $\begin{array}{c}-0.0279 * * * \\
(0.0054)\end{array}$ & $\begin{array}{c}-0.0352 * * * \\
(0.0050)\end{array}$ & $\begin{array}{l}-0.0152 \\
(0.0101)\end{array}$ & $\begin{array}{c}-0.0204 * * * \\
(0.0050)\end{array}$ \\
\hline $\begin{array}{l}\text { High cost mandates } \times \\
\text { potential experience }\end{array}$ & $\begin{array}{c}0.0022 * * * \\
(0.0003)\end{array}$ & $\begin{array}{c}0.0033 * * * \\
(0.0004)\end{array}$ & $\begin{array}{c}0.0018 * * * \\
(0.0003) \\
\end{array}$ & $\begin{array}{c}0.0021 * * * \\
(0.0003)\end{array}$ \\
\hline Unweighted observations & 176,761 & 278,728 & 290,164 & 290,164 \\
\hline
\end{tabular}

Notes: All models estimated with least squares (continuous variables) or a linear probability model (binary variables), and control for demographics, labor market entrance state fixed effects, and labor market entrance year fixed effects. CPS sample weights applied. Standard errors are clustered around the state and reported in parentheses.

${ }^{1} \mathrm{ESI}=$ Hold employer-sponsored health insurance. This variable is only available 1980-2013.

$* * * ; * * * *=$ statistically different from zero at the $1 \% ; 5 \% ; 10 \%$ level.

Appendix Table B2. The persistent effect of high cost mandates at labor market entrance on ESI and labor market outcomes among private, non-self-employed workers: Current Population Survey 1976-2013

\begin{tabular}{|c|c|c|c|c|}
\hline Outcome: & ESI $^{1}$ & "Log(wages) & Log(weeks) & Full-time \\
\hline \multicolumn{5}{|l|}{ Men } \\
\hline Sample proportion/mean & 0.788 & 17.77 & 44.28 & 0.864 \\
\hline High cost mandates & $\begin{array}{c}-0.0313 * * * \\
(0.0039)\end{array}$ & $\begin{array}{c}-0.0549 * * * \\
(0.0072)\end{array}$ & $\begin{array}{c}-0.0359 * * * \\
(0.0093)\end{array}$ & $\begin{array}{c}-0.0337 * * * \\
(0.0043)\end{array}$ \\
\hline $\begin{array}{l}\text { High cost mandates } \times \\
\text { potential experience }\end{array}$ & $\begin{array}{c}0.0027 * * * \\
(0.0003)\end{array}$ & $\begin{array}{c}0.0048 * * * \\
(0.0005)\end{array}$ & $\begin{array}{c}0.0033 * * * \\
(0.0004)\end{array}$ & $\begin{array}{c}0.0032 * * * \\
(0.0004)\end{array}$ \\
\hline Unweighted observations & 181,351 & 268,162 & 269,225 & 269,225 \\
\hline \multicolumn{5}{|l|}{ Women } \\
\hline Sample proportion/mean & 0.723 & 14.06 & 42.08 & 0.715 \\
\hline High cost mandates & $\begin{array}{c}-0.0245 * * * \\
(0.0051)\end{array}$ & $\begin{array}{c}-0.0328 * * * \\
(0.0051)\end{array}$ & $\begin{array}{l}-0.0150 \\
(0.0104)\end{array}$ & $\begin{array}{c}-0.0206 * * * \\
(0.0057)\end{array}$ \\
\hline $\begin{array}{l}\text { High cost mandates } \times \\
\text { potential experience }\end{array}$ & $\begin{array}{c}0.0023 * * * \\
(0.0003)\end{array}$ & $\begin{array}{c}0.0033 * * * \\
(0.0004)\end{array}$ & $\begin{array}{c}0.0019 * * * \\
(0.0003)\end{array}$ & $\begin{array}{c}0.0022 * * * \\
(0.0003)\end{array}$ \\
\hline Unweighted observations & 141,515 & 235,740 & 236,751 & 236,751 \\
\hline
\end{tabular}

Notes: Non-employed, non-private, and self-employed workers excluded from the sample. All models estimated with least squares (continuous variables) or a linear probability model (binary variables), and control for demographics, labor market entrance state fixed effects, and labor market entrance year fixed effects. CPS sample weights applied. Standard errors are clustered around the state and reported in parentheses.

${ }^{1} \mathrm{ESI}=$ Hold employer-sponsored health insurance. This variable is only available 1980-2013.

$* * * ; * * * *=$ statistically different from zero at the $1 \% ; 5 \% ; 10 \%$ level. 
Appendix Table C. The persistent effect of high cost mandates at labor market entrance on ESI access and labor market outcomes using a weighted count of high cost mandates: NLSY79 1979-2012

\begin{tabular}{|c|c|c|c|c|}
\hline Outcome: & ESI $^{1}$ & Log(wages) & Log(weeks) & Full-time \\
\hline \multicolumn{5}{|l|}{ Male sample } \\
\hline Sample proportion/mean & 0.790 & 22.08 & 46.11 & 0.897 \\
\hline High cost mandates & $\begin{array}{l}-0.0047 \\
(0.0033)\end{array}$ & $\begin{array}{l}-0.0107^{*} \\
(0.0058)\end{array}$ & $\begin{array}{l}-0.0055^{*} \\
(0.0029)\end{array}$ & $\begin{array}{c}-0.0085 * * * \\
(0.0027)\end{array}$ \\
\hline $\begin{array}{l}\text { High cost mandates } \times \\
\text { potential experience }\end{array}$ & $\begin{array}{c}0.0000 \\
(0.0001)\end{array}$ & $\begin{array}{c}0.0010 * * * \\
(0.0003)\end{array}$ & $\begin{array}{l}0.0004 * * \\
(0.0001)\end{array}$ & $\begin{array}{c}0.0006^{* * *} \\
(0.0001) \\
\end{array}$ \\
\hline Unweighted observations & 68,464 & 79,806 & 83,489 & 82,179 \\
\hline \multicolumn{5}{|l|}{ Female sample } \\
\hline Sample proportion/mean & 0.761 & 16.68 & 43.95 & 0.724 \\
\hline High cost mandates & $\begin{array}{l}-0.0033 \\
(0.0034)\end{array}$ & $\begin{array}{c}-0.0109 * * * \\
(0.0034)\end{array}$ & $\begin{array}{c}0.0023 \\
(0.0037)\end{array}$ & $\begin{array}{c}-0.0073 * * \\
(0.0033)\end{array}$ \\
\hline $\begin{array}{l}\text { High cost mandates } \times \\
\text { potential experience }\end{array}$ & $\begin{array}{c}0.0002 \\
(0.0002) \\
\end{array}$ & $\begin{array}{c}0.0008 * * * \\
(0.0002)\end{array}$ & $\begin{array}{l}-0.0002 * \\
(0.0001) \\
\end{array}$ & $\begin{array}{c}0.0003 \\
(0.0002) \\
\end{array}$ \\
\hline Unweighted observations & 64,163 & 76,596 & 80,012 & 78,855 \\
\hline
\end{tabular}

Notes: All models estimated with least squares (continuous variables) or a linear probability model (binary variables), and control for demographics, labor market entrance state fixed effects, and labor market entrance year fixed effects. NLSY79 sample weights applied. Standard errors are clustered around the labor market entrance state and reported in parentheses. The weighted mandate count is using the following formula: alcohol mandate + illicit drug mandate $+5 *$ mental health mandate $+1.5 *$ chiropractor mandate $+3 *$ continuing coverage mandate. $* * * ; * ; *=$ statistically different from zero at the $1 \% ; 5 \% ; 10 \%$ level.

${ }^{1} \mathrm{ESI}=$ Employer-sponsored health insurance offer. 
Appendix Table D1. Effect of high cost mandates at labor market entrance on labor market outcomes by worker skill at labor market entrance: NLSY79 men 1979-2012

\begin{tabular}{lcccc}
\hline \hline Outcome: & ESI $^{\mathbf{1}}$ & Log(wages) & Log(weeks) & Full-time \\
\hline Lesser skill workers $^{2}$ & & & & \\
\hline Sample proportion/mean & 0.752 & 18.50 & 45.39 & 0.899 \\
\hline High cost mandates & $-0.0298^{* *}$ & $-0.0382^{* *}$ & $-0.0198^{*}$ & $-0.0221^{* * *}$ \\
& $(0.0136)$ & $(0.0157)$ & $(0.0100)$ & $(0.0050)$ \\
High cost mandates $\times$ & 0.0007 & $0.0021^{* * *}$ & $0.0010^{* *}$ & $0.0017^{* * *}$ \\
potential experience & $(0.0005)$ & $(0.0006)$ & $(0.0005)$ & $(0.0003)$ \\
\hline Unweighted observations & 48,413 & 57,532 & 60,000 & 59,036 \\
\hline Higher skill workers & & & & \\
\hline Sample proportion/mean & 0.841 & 25.00 & 46.64 & 0.805 \\
\hline High cost mandates & 0.0111 & -0.0118 & -0.0044 & -0.0174 \\
& $(0.0164)$ & $(0.0265)$ & $(0.0119)$ & $(0.0113)$ \\
High cost mandates $\times$ & 0.0006 & $0.0020^{*}$ & $0.0017^{* * *}$ & $0.0013^{* * *}$ \\
potential experience & $(0.0005)$ & $(0.0012)$ & $(0.0006)$ & $0.0004)$ \\
\hline Unweighted observations & 20,051 & 22,274 & 23,489 & 23,143 \\
\hline
\end{tabular}

Notes: All models estimated with least squares (continuous variables) or a linear probability model (binary variables), and control for demographics, labor market entrance state fixed effects, and labor market entrance year fixed effects. NLSY79 sample weights applied. Standard errors are clustered around the labor market entrance state and reported in parentheses.

$* * * ; * * *=$ statistically different from zero at the $1 \% ; 5 \% ; 10 \%$ level.

${ }^{1} \mathrm{ESI}=$ Employer-sponsored health insurance offer.

${ }^{2}$ Lesser skill workers $=$ A high school diploma or less at labor market entrance.

${ }^{3}$ Higher skill workers $=$ Some college at labor market entrance. 
Appendix Table D2. Effect of high cost mandates at labor market entrance on labor market outcomes by worker skill at labor market entrance: NLSY79 women 1979-2012

\begin{tabular}{|c|c|c|c|c|}
\hline Outcome: & ESI $^{1}$ & Log(wages) & Log(weeks) & Full-time \\
\hline \multicolumn{5}{|l|}{ Lesser skill workers ${ }^{2}$} \\
\hline Sample proportion/mean & 0.725 & 14.07 & 42.81 & 0.723 \\
\hline High cost mandates & $\begin{array}{l}-0.0107 \\
(0.0104)\end{array}$ & $\begin{array}{l}-0.0286^{*} \\
(0.0144)\end{array}$ & $\begin{array}{l}-0.0043 \\
(0.0142)\end{array}$ & $\begin{array}{c}-0.0259 * * * \\
(0.0093)\end{array}$ \\
\hline $\begin{array}{l}\text { High cost mandates } \times \\
\text { potential experience }\end{array}$ & $\begin{array}{c}0.0003 \\
(0.0005)\end{array}$ & $\begin{array}{c}0.0019 * * * \\
(0.0005)\end{array}$ & $\begin{array}{l}-0.0003 \\
(0.0005)\end{array}$ & $\begin{array}{c}0.0009 * * \\
(0.0004)\end{array}$ \\
\hline Unweighted observations & 40,760 & 49,647 & 51,634 & 50,892 \\
\hline \multicolumn{5}{|l|}{ Higher skill workers ${ }^{3}$} \\
\hline Sample proportion/mean & 0.863 & 29.36 & 47.55 & 0.891 \\
\hline High cost mandates & $\begin{array}{l}-0.0222 \\
(0.0141)\end{array}$ & $\begin{array}{l}-0.0187 \\
(0.0188)\end{array}$ & $\begin{array}{c}0.0029 \\
(0.0111)\end{array}$ & $\begin{array}{c}-0.0342^{* *} \\
(0.0150)\end{array}$ \\
\hline $\begin{array}{l}\text { High cost mandates } \times \\
\text { potential experience }\end{array}$ & $\begin{array}{l}0.0009 * \\
(0.0005)\end{array}$ & $\begin{array}{c}0.0018 \\
(0.0011)\end{array}$ & $\begin{array}{c}0.0002 \\
(0.0005)\end{array}$ & $\begin{array}{c}0.0008 \\
(0.0007)\end{array}$ \\
\hline Unweighted observations & 23,403 & 26,949 & 28,378 & 27,963 \\
\hline
\end{tabular}

Notes: All models estimated with least squares (continuous variables) or a linear probability model (binary variables), and control for demographics, labor market entrance state fixed effects, and labor market entrance year fixed effects. NLSY79 sample weights applied. Standard errors are clustered around the labor market entrance state and reported in parentheses.

$* * * * * ; *=$ statistically different from zero at the $1 \% ; 5 \% ; 10 \%$ level.

${ }^{1} \mathrm{ESI}=$ Employer-sponsored health insurance offer.

${ }^{2}$ Lesser skill workers $=\mathrm{A}$ high school diploma or less at labor market entrance.

${ }^{3}$ Higher skill workers=Some college at labor market entrance. 
Appendix Table E1. Effect of high cost mandates at labor market entrance on labor market outcomes by union status at labor market entrance: NLSY79 men 1979-2012

\begin{tabular}{lcccc}
\hline Outcome: & ESI $^{\mathbf{1}}$ & Log(wages) & Log(weeks) & Full-time \\
\hline Unionized & & & & \\
\hline Sample proportion/mean & 0.857 & 22.23 & 47.31 & 0.924 \\
\hline High cost mandates & -0.0102 & -0.0450 & $0.0433^{* *}$ & -0.0051 \\
& $(0.0211)$ & $(0.0302)$ & $(0.0163)$ & $(0.0135)$ \\
High cost mandates $\times$ & 0.0000 & 0.0016 & -0.0005 & 0.0006 \\
potential experience & $(0.0009)$ & $(0.0017)$ & $(0.0005)$ & $(0.0008)$ \\
\hline Unweighted observations & 8,204 & 9,221 & 9,418 & 9,324 \\
\hline Non-unionized & & & & \\
\hline Sample proportion/mean & 0.780 & 22.06 & 45.94 & 0.893 \\
\hline High cost mandates & -0.0141 & $-0.0415^{* *}$ & $-0.0250^{* * *}$ & $-0.0242^{* * *}$ \\
& $(0.0092)$ & $(0.0167)$ & $(0.0083)$ & $(0.0056)$ \\
High cost mandates $\times$ & $0.0006^{*}$ & $0.0034^{* * *}$ & $0.0014^{* * *}$ & $0.0019^{* * *}$ \\
potential experience & $(0.0003)$ & $(0.0008)$ & $(0.0004)$ & $0.0003)$ \\
\hline Unweighted observations & 60,260 & 70,585 & 74,071 & 72,855 \\
\hline Notes & & &
\end{tabular}

Notes: All models estimated with least squares (continuous variables) or a linear probability model (binary variables), and control for demographics, labor market entrance state fixed effects, and labor market entrance year fixed effects. NLSY79 sample weights applied. Standard errors are clustered around the labor market entrance state and reported in parentheses.

$* * * ; * ; *=$ statistically different from zero at the $1 \% ; 5 \% ; 10 \%$ level.

${ }^{1} \mathrm{ESI}=$ Employer-sponsored health insurance offer.

Appendix Table E2. Effect of high cost mandates at labor market entrance on labor market outcomes by union status at labor market entrance: NLSY79 women 1979-2012

\begin{tabular}{lcccc}
\hline \hline Outcome: & ESI $^{\mathbf{1}}$ & Log(wages) & \multicolumn{1}{l}{ Log(weeks) } & Full-time \\
\hline Unionized & & & & \\
\hline Sample proportion/mean & 0.829 & 17.61 & 45.73 & 0.759 \\
\hline High cost mandates & 0.0023 & -0.0399 & 0.0143 & -0.0244 \\
& $(0.0191)$ & $(0.0331)$ & $(0.0234)$ & $(0.0300)$ \\
High cost mandates $\times$ & $0.0020^{* *}$ & $0.0050^{* * *}$ & 0.0013 & $0.0030^{* * *}$ \\
potential experience & $(0.0008)$ & $(0.0012)$ & $(0.0008)$ & $(0.0011)$ \\
\hline Unweighted observations & 4,772 & 5,517 & 5,694 & 5,598 \\
\hline Non-unionized & \multicolumn{5}{c}{} & \\
\hline Sample proportion/mean & 0.756 & 16.61 & 43.81 & 0.721 \\
\hline High cost mandates & $-0.0176^{* *}$ & $-0.0309^{* * *}$ & -0.0002 & $-0.0261^{* * *}$ \\
& $(0.0075)$ & $(0.0098)$ & $(0.0091)$ & $(0.0084)$ \\
High cost mandates $\times$ & 0.0004 & $0.0021^{* * *}$ & -0.0004 & 0.0006 \\
potential experience & $(0.0004)$ & $(0.0005)$ & $(0.0003)$ & $(0.0005)$ \\
\hline Unweighted observations & 59,391 & 71,079 & 74,318 & 73,257
\end{tabular}

Notes: All models estimated with least squares (continuous variables) or a linear probability model (binary variables), and control for demographics, labor market entrance state fixed effects, and labor market entrance year fixed effects. NLSY79 sample weights applied. Standard errors are clustered around the labor market entrance state and reported in parentheses.

$* * * ; * ; *=$ statistically different from zero at the $1 \% ; 5 \% ; 10 \%$ level.

${ }^{1} \mathrm{ESI}=$ Employer-sponsored health insurance offer. 
Appendix Table F1. The persistent effect of alcohol treatment mandates at labor market entrance on ESI access and labor market outcomes: NLSY79 1979-2012

\begin{tabular}{|c|c|c|c|c|}
\hline Outcome: & ESI $^{1}$ & Log(wages) & Log(weeks) & Full-time \\
\hline \multicolumn{5}{|l|}{ Male sample } \\
\hline Sample proportion/mean & 0.790 & 22.08 & 46.11 & 0.897 \\
\hline Alcohol treatment mandate & $\begin{array}{c}0.0031 \\
(0.0228)\end{array}$ & $\begin{array}{c}-0.1099 * * * \\
(0.0302)\end{array}$ & $\begin{array}{l}-0.0332^{*} \\
(0.0184)\end{array}$ & $\begin{array}{c}-0.0454 * * * \\
(0.0136)\end{array}$ \\
\hline $\begin{array}{l}\text { Alcohol treatment mandate } \times \\
\text { potential experience }\end{array}$ & $\begin{array}{c}0.0006 \\
(0.0007)\end{array}$ & $\begin{array}{c}0.0083 * * * \\
(0.0018)\end{array}$ & $\begin{array}{l}0.0023 * * \\
(0.0010)\end{array}$ & $\begin{array}{c}0.0031 * * * \\
(0.0009)\end{array}$ \\
\hline Unweighted observations & 68,464 & 79,806 & 83,489 & 82,179 \\
\hline \multicolumn{5}{|l|}{ Female sample } \\
\hline Sample proportion/mean & 0.761 & 16.68 & 43.95 & 0.724 \\
\hline Alcohol mandate & $\begin{array}{l}-0.0174 \\
(0.0138)\end{array}$ & $\begin{array}{l}-0.0349 \\
(0.0244)\end{array}$ & $\begin{array}{c}0.0237 \\
(0.0167)\end{array}$ & $\begin{array}{l}-0.0092 \\
(0.0213)\end{array}$ \\
\hline $\begin{array}{l}\text { Alcohol treatment mandate } \times \\
\text { potential experience }\end{array}$ & $\begin{array}{c}0.0006 \\
(0.0008)\end{array}$ & $\begin{array}{c}0.0041 * * * \\
(0.0012)\end{array}$ & $\begin{array}{c}-0.0015 * * \\
(0.0007)\end{array}$ & $\begin{array}{c}0.0002 \\
(0.0012)\end{array}$ \\
\hline Unweighted observations & 64,163 & 76,596 & 80,012 & 78,855 \\
\hline
\end{tabular}

Notes: All models estimated with least squares (continuous variables) or a linear probability model (binary variables), and control for demographics, labor market entrance state fixed effects, and labor market entrance year fixed effects. NLSY79 sample weights applied. Standard errors are clustered around the labor market entrance state and reported in parentheses.

${ }^{1} \mathrm{ESI}=$ Employer-sponsored health insurance offer.

$* * * ; * * * *=$ statistically different from zero at the $1 \% ; 5 \% ; 10 \%$ level. 
Appendix Table F2. The persistent effect of illicit drug treatment mandates at labor market entrance on ESI access and labor market outcomes: NLSY79 1979-2012

\begin{tabular}{lcccc}
\hline Outcome: & ESI $^{\mathbf{1}}$ & Log(wages) & Log(weeks) & Full-time \\
\hline Male sample & & & & \\
\hline Sample proportion/mean & 0.790 & 22.08 & 46.11 & 0.897 \\
\hline Illicit drug treatment & -0.0195 & -0.0411 & -0.0335 & $-0.0318^{* * *}$ \\
mandate & $(0.0294)$ & $(0.0441)$ & $(0.0222)$ & $(0.0111)$ \\
Illicit drug treatment mandate & 0.0004 & $0.0041^{*}$ & $0.0032^{* *}$ & $0.0039^{* * *}$ \\
potential experience & $(0.0012)$ & $(0.0023)$ & $(0.0013)$ & $(0.0008)$ \\
\hline Unweighted observations & 68,464 & 79,806 & 83,489 & 82,179 \\
\hline Female sample & & & 43.95 & 0.724 \\
\hline Sample proportion/mean & 0.761 & 16.68 & 0.0076 & $-0.0768^{* * *}$ \\
\hline Illicit drug treatment & -0.0115 & -0.0347 & $(0.0209)$ & $(0.0230)$ \\
mandate & $(0.0272)$ & $(0.0300)$ & 0.0002 & $0.0029^{* * *}$ \\
Illicit drug treatment mandate $\times$ & $0.0018 *$ & $0.0046 * * *$ & $(0.0010)$ & $(0.0011)$ \\
potential experience & $(0.0011)$ & $(0.0014)$ & 80,012 & 78,855 \\
\hline Unweighted observations & 64,163 & 76,596 & & \\
\hline
\end{tabular}

Notes: All models estimated with least squares (continuous variables) or a linear probability model (binary variables), and control for demographics, labor market entrance state fixed effects, and labor market entrance year fixed effects. NLSY79 sample weights applied. Standard errors are clustered around the labor market entrance state and reported in parentheses.

${ }^{1} \mathrm{ESI}=$ Employer-sponsored health insurance offer.

$* * * ; * * * *=$ statistically different from zero at the $1 \% ; 5 \% ; 10 \%$ level. 
Appendix Table F3. The persistent effect of mental health treatment at labor market entrance on ESI access and labor market outcomes: NLSY79 1979-2012

\begin{tabular}{|c|c|c|c|c|}
\hline Outcome: & ESI $^{1}$ & Log(wages) & Log(weeks) & Full-time \\
\hline \multicolumn{5}{|l|}{ Male sample } \\
\hline Sample proportion/mean & 0.790 & 22.08 & 46.11 & 0.897 \\
\hline Mental health treatment & $\begin{array}{l}-0.0112 \\
(0.0251)\end{array}$ & $\begin{array}{l}-0.0054 \\
(0.0461)\end{array}$ & $\begin{array}{l}-0.0320 \\
(00195)\end{array}$ & $-0.0452 * *$ \\
\hline Mental health treatment & -0.0011 & 0.0023 & $0.0019 *$ & $0.0023 * * *$ \\
\hline mandate $\times$ potential experience & $(0.0008)$ & $(0.0024)$ & $(0.0010)$ & $(0.0008)$ \\
\hline Unweighted observations & 68,464 & 79,806 & 83,489 & 82,179 \\
\hline \multicolumn{5}{|l|}{ Female sample } \\
\hline Sample proportion/mean & 0.761 & 16.68 & 43.95 & 0.724 \\
\hline Mental health treatment & -0.0082 & -0.0194 & 0.0376 & -0.0174 \\
\hline mandate & $(0.0285)$ & $(0.0241)$ & $(0.0272)$ & $(0.0243)$ \\
\hline Mental health treatment & 0.0014 & $0.0047 * * *$ & $-0.0015 * *$ & 0.0015 \\
\hline mandate $\times$ potential experience & $(0.0011)$ & $(0.0010)$ & $(0.0007)$ & $(0.0013)$ \\
\hline Unweighted observations & 64,163 & 76,596 & 80,012 & 78,855 \\
\hline
\end{tabular}

Notes: All models estimated with least squares (continuous variables) or a linear probability model (binary variables), and control for demographics, labor market entrance state fixed effects, and labor market entrance year fixed effects. NLSY79 sample weights applied. Standard errors are clustered around the labor market entrance state and reported in parentheses.

${ }^{1} \mathrm{ESI}=$ Employer-sponsored health insurance offer.

$* * * ; * * *=$ statistically different from zero at the $1 \% ; 5 \% ; 10 \%$ level. 
Appendix Table F4. The persistent effect of chiropractor mandates at labor market entrance on ESI access and labor market outcomes: NLSY79 1979-2012

\begin{tabular}{lcccc}
\hline \hline Outcome: & ESI $^{\mathbf{1}}$ & Log(wages) & Log(weeks) & Full-time \\
\hline Male sample & & & & \\
\hline Sample proportion/mean & 0.790 & 22.08 & 46.11 & 0.897 \\
\hline Chiropractor mandate & $-0.0509^{*}$ & -0.0076 & -0.0076 & 0.0009 \\
& $(0.0274)$ & $(0.0447)$ & $(0.0225)$ & $(0.0140)$ \\
Chiropractor mandate $\times$ & $0.0025^{* * *}$ & 0.0004 & 0.0008 & 0.0004 \\
potential experience & $(0.0007)$ & $(0.0018)$ & $(0.0007)$ & $(0.0008)$ \\
\hline Unweighted observations & 68,464 & 79,806 & 83,489 & 82,179 \\
\hline Female sample & & & & \\
\hline Sample proportion/mean & 0.761 & 16.68 & 43.95 & 0.724 \\
\hline Chiropractor mandate & $-0.0528^{* *}$ & 0.0015 & $-0.0494^{*}$ & $-0.0523^{* *}$ \\
& $(0.0206)$ & $(0.0292)$ & $(0.0287)$ & $(0.0233)$ \\
Chiropractor mandate & 0.0005 & -0.0005 & 0.0013 & 0.0006 \\
potential experience & $(0.0008)$ & $(0.0011)$ & $(0.0008)$ & $(0.0010)$ \\
\hline Unweighted observations & 64,163 & 76,596 & 80,012 & 78,855 \\
\hline Notes All & & &
\end{tabular}

Notes: All models estimated with least squares (continuous variables) or a linear probability model (binary variables), and control for demographics, labor market entrance state fixed effects, and labor market entrance year fixed effects. NLSY79 sample weights applied. Standard errors are clustered around the labor market entrance state and reported in parentheses.

${ }^{1}$ ESI=Employer-sponsored health insurance offer.

$* * * * * ; *=$ statistically different from zero at the $1 \% ; 5 \% ; 10 \%$ level. 
Appendix Table F5. The persistent effect of continuing coverage mandates at labor market entrance on ESI access and labor market outcomes: NLSY79 1979-2012

\begin{tabular}{|c|c|c|c|c|}
\hline Outcome: & ESI $^{1}$ & Log(wages) & Log(weeks) & Full-time \\
\hline \multicolumn{5}{|l|}{ Male sample } \\
\hline Sample proportion/mean & 0.790 & 22.08 & 46.11 & 0.897 \\
\hline $\begin{array}{l}\text { Continuing coverage } \\
\text { mandate }\end{array}$ & $\begin{array}{l}-0.0219 \\
(0.0208)\end{array}$ & $\begin{array}{c}-0.1193 * * * \\
(0.0340)\end{array}$ & $\begin{array}{l}-0.0176 \\
(0.0222)\end{array}$ & $\begin{array}{c}-0.0548 * * * \\
(0.0159)\end{array}$ \\
\hline $\begin{array}{l}\text { Continuing coverage } \\
\text { mandate } \times \text { potential experience }\end{array}$ & $\begin{array}{c}0.0004 \\
(0.0010)\end{array}$ & $\begin{array}{l}0.0089 * * * \\
(0.0020)\end{array}$ & $\begin{array}{c}0.0014 \\
(0.0015)\end{array}$ & $\begin{array}{c}0.0045 * * * \\
(0.0008)\end{array}$ \\
\hline Unweighted observations & 68,464 & 79,806 & 83,489 & 82,179 \\
\hline \multicolumn{5}{|l|}{ Female sample } \\
\hline Sample proportion/mean & 0.761 & 16.68 & 43.95 & 0.724 \\
\hline $\begin{array}{l}\text { Continuing coverage } \\
\text { mandate }\end{array}$ & $\begin{array}{c}0.0026 \\
(0.0250)\end{array}$ & $\begin{array}{l}-0.1131 * * * \\
(0.0309)\end{array}$ & $\begin{array}{c}0.0038 \\
(0.0211)\end{array}$ & $\begin{array}{l}-0.0343 \\
(0.0275)\end{array}$ \\
\hline $\begin{array}{l}\text { Continuing coverage } \\
\text { mandate } \times \text { potential experience }\end{array}$ & $\begin{array}{l}-0.0008 \\
(0.0009)\end{array}$ & $\begin{array}{c}0.0045 * * * \\
(0.0017)\end{array}$ & $\begin{array}{l}-0.0015 \\
(0.0009)\end{array}$ & $\begin{array}{c}0.0015 \\
(0.0015) \\
\end{array}$ \\
\hline Unweighted observations & 64,163 & 76,596 & 80,012 & 78,855 \\
\hline
\end{tabular}

Notes: All models estimated with least squares (continuous variables) or a linear probability model (binary variables), and control for demographics, labor market entrance state fixed effects, and labor market entrance year fixed effects. NLSY79 sample weights applied. Standard errors are clustered around the labor market entrance state and reported in parentheses.

${ }^{1} \mathrm{ESI}=$ Employer-sponsored health insurance offer.

$* * * ; * * * *=$ statistically different from zero at the $1 \% ; 5 \% ; 10 \%$ level. 
Appendix Table G. The persistent effect of high cost mandates at labor market entrance on ESI access and labor market outcomes include contemporaneous high cost mandates: NLSY79 1979-2012

\begin{tabular}{|c|c|c|c|c|}
\hline Outcome: & ESI $^{1}$ & Log(wages) & Log(weeks) & Full-time \\
\hline \multicolumn{5}{|l|}{ Male sample } \\
\hline Sample proportion/mean & 0.790 & 22.08 & 46.11 & 0.897 \\
\hline High cost mandates & $\begin{array}{l}-0.0134 \\
(0.0081)\end{array}$ & $\begin{array}{c}-0.0396^{* *} \\
(0.0153)\end{array}$ & $\begin{array}{c}-0.0165 * * \\
(0.0081)\end{array}$ & $\begin{array}{c}-0.0227 * * * \\
(0.0055)\end{array}$ \\
\hline $\begin{array}{l}\text { High cost mandates } \times \\
\text { potential experience }\end{array}$ & $\begin{array}{c}0.0006 \\
(0.0003)\end{array}$ & $\begin{array}{c}0.0032 * * * \\
(0.0008)\end{array}$ & $\begin{array}{c}0.0013 * * * \\
(0.0004)\end{array}$ & $\begin{array}{c}0.0018 * * * \\
(0.0003)\end{array}$ \\
\hline Unweighted observations & 68,464 & 79,806 & 83,489 & 82,179 \\
\hline \multicolumn{5}{|l|}{ Female sample } \\
\hline Sample proportion/mean & 0.761 & 16.68 & 43.95 & 0.724 \\
\hline High cost mandates & $\begin{array}{l}-0.0121 \\
(0.0074)\end{array}$ & $\begin{array}{c}-0.0264 * * * \\
(0.0088)\end{array}$ & $\begin{array}{c}0.0024 \\
(0.0087)\end{array}$ & $\begin{array}{c}-0.0231 * * * \\
(0.0076)\end{array}$ \\
\hline $\begin{array}{l}\text { High cost mandates } \times \\
\text { potential experience }\end{array}$ & $\begin{array}{c}0.0004 \\
(0.0004)\end{array}$ & $\begin{array}{c}0.0021 * * * \\
(0.0005)\end{array}$ & $\begin{array}{l}-0.0004 \\
(0.0003)\end{array}$ & $\begin{array}{c}0.0007 \\
(0.0004) \\
\end{array}$ \\
\hline Unweighted observations & 64,163 & 76,596 & 80,012 & 78,855 \\
\hline
\end{tabular}

Notes: All models estimated with least squares (continuous variables) or a linear probability model (binary variables), and control for demographics, labor market entrance state fixed effects, and labor market entrance year fixed effects. NLSY79 sample weights applied. Standard errors are clustered around the labor market entrance state and reported in parentheses.

${ }^{1} \mathrm{ESI}=$ Employer-sponsored health insurance offer.

$* * * ; * * *=$ statistically different from zero at the $1 \% ; 5 \% ; 10 \%$ level. 
Appendix Table H1. The persistent effect of high cost mandates at labor market entrance on ESI access and labor market outcomes allowing for a more flexible relationship of mandate effects over time among men:

NLSY79 1979-2012

\begin{tabular}{lcccc}
\hline \hline Outcome: & ESI $^{\mathbf{1}}$ & Log(wages) & Log(weeks) & Full-time \\
\hline Sample proportion/mean & 0.790 & 22.08 & 46.11 & 0.897 \\
\hline 1 -10 years & -0.0081 & $-0.0204^{*}$ & -0.0016 & -0.0052 \\
& $(0.0068)$ & $(0.0121)$ & $(0.0063)$ & $(0.0048)$ \\
$11-20$ years & -0.0019 & $0.0293^{* *}$ & -0.0006 & 0.0059 \\
& $(0.0084)$ & $(0.0112)$ & $(0.0060)$ & $(0.0044)$ \\
11 years+ & -0.0079 & 0.0137 & 0.0031 & 0.0061 \\
& $(0.0078)$ & $(0.0141)$ & $(0.0060)$ & $(0.0052)$ \\
\hline Unweighted observations & 68,464 & 79,806 & 83,489 & 82,179 \\
\hline
\end{tabular}

Notes: All models estimated with least squares (continuous variables) or a linear probability model (binary variables), and control for demographics, labor market entrance state fixed effects, and labor market entrance year fixed effects. NLSY79 sample weights applied. Standard errors are clustered around the labor market entrance state and reported in parentheses.

${ }^{1} \mathrm{ESI}=$ Employer-sponsored health insurance offer.

$* * * ; * * * *=$ statistically different from zero at the $1 \% ; 5 \% ; 10 \%$ level. 
Appendix Table H2. The persistent effect of high cost mandates at labor market entrance on ESI access and labor market outcomes allowing for a more flexible relationship of mandate effects over time among women: NLSY79 1979-2012

\begin{tabular}{|c|c|c|c|c|}
\hline Outcome: & ESI $^{1}$ & Log(wages) & Log(weeks) & Full-time \\
\hline Sample proportion/mean & 0.761 & 16.68 & 43.95 & 0.724 \\
\hline \multirow{2}{*}{$1-10$ years } & -0.0051 & -0.0091 & 0.0066 & -0.0099 \\
\hline & $(0.0060)$ & $(0.0077)$ & $(0.0075)$ & $(0.0067)$ \\
\hline \multirow[t]{2}{*}{$11-20$ years } & -0.0048 & 0.0112 & -0.0118 & $-0.0201 * * *$ \\
\hline & $(0.0061)$ & $(0.0070)$ & $(0.0076)$ & $(0.0075)$ \\
\hline \multirow[t]{2}{*}{21 years +} & -0.0091 & 0.0115 & -0.0088 & -0.0139 \\
\hline & $(0.0064)$ & $(0.0108)$ & $(0.0065)$ & $(0.0088)$ \\
\hline Unweighted observations & 64,163 & 76,596 & 80,012 & 78,855 \\
\hline
\end{tabular}

Notes: All models estimated with least squares (continuous variables) or a linear probability model (binary variables), and control for demographics, labor market entrance state fixed effects, and labor market entrance year fixed effects. NLSY79 sample weights applied. Standard errors are clustered around the labor market entrance state and reported in parentheses.

${ }^{1} \mathrm{ESI}=$ Employer-sponsored health insurance offer.

$* * * ; * * * *=$ statistically different from zero at the $1 \% ; 5 \% ; 10 \%$ level. 
Figure 1. The effect of mandated benefits on wages and employment

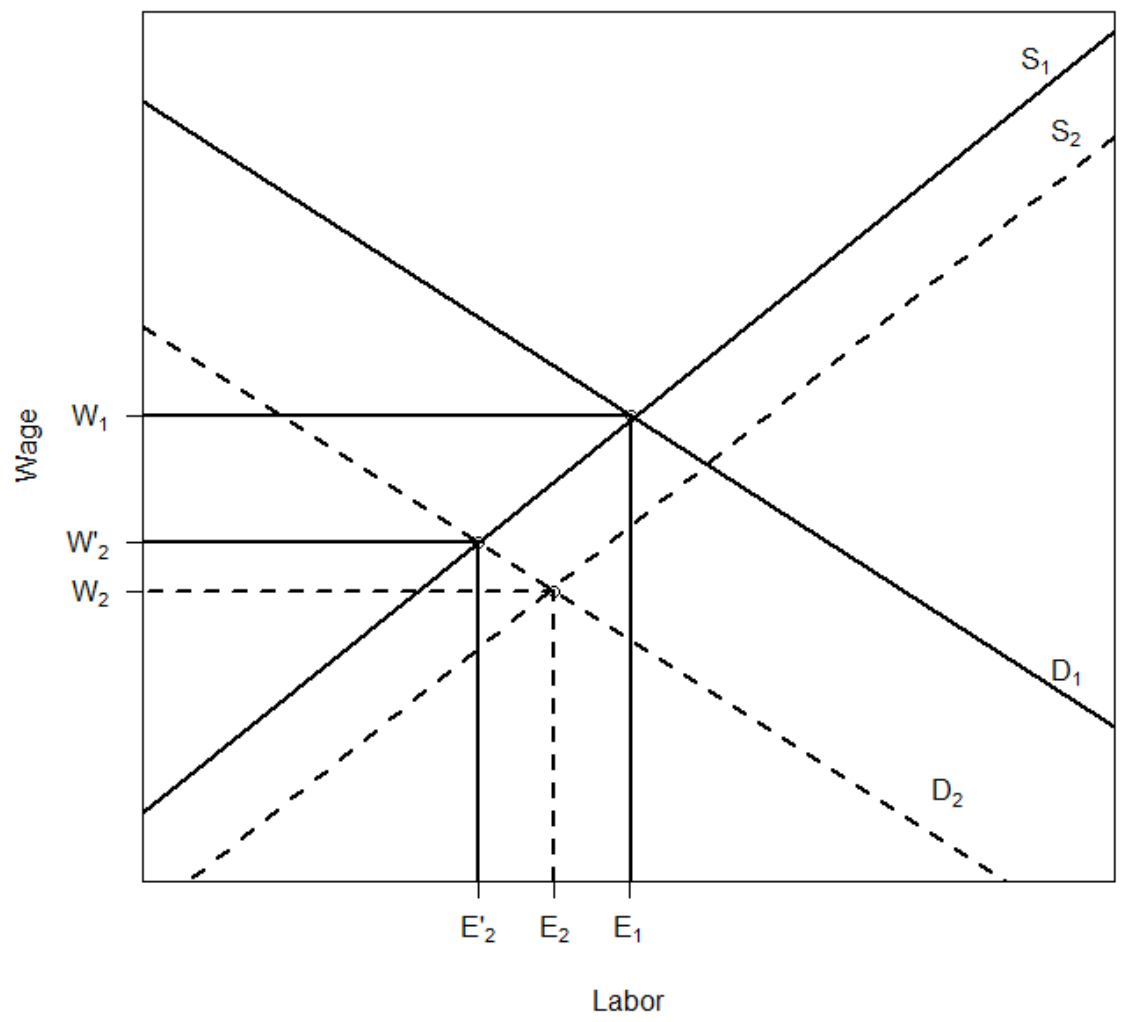

Notes: Figure based on Summers (1989). The magnitude of the shifts in the demand and supply curves are arbitrarily chosen and are for illustrative purposes only. 
Supplementary Appendix Table 1. The persistent effect of high cost mandates at labor market entrance on usual hours worked per week and non-logged hourly wages and weeks worked: NLSY79 1979-2012

\begin{tabular}{lccc}
\hline Outcome: & Log(hours) & Wages (not logged) & Weeks (not logged) \\
\hline Male sample & & & \\
\hline Sample mean (non-transformed) & 44.67 & 22.08 & 46.11 \\
\hline High cost mandates & $-0.0220^{* * *}$ & $-1.4011^{* *}$ & $-0.4239^{*}$ \\
& $(0.0076)$ & $(0.5499)$ & $(0.2171)$ \\
High cost mandates $\times$ & $0.0017^{* * *}$ & $0.1060^{* * *}$ & $0.0354^{* * *}$ \\
potential experience & $(0.0002)$ & $(0.0338)$ & $(0.0094)$ \\
\hline Unweighted observations & 82,160 & 79,806 & 83,489 \\
\hline Female sample & & & 43.95 \\
\hline Sample mean (non-transformed) & 37.60 & 16.68 & 0.0882 \\
\hline High cost mandates & $-0.0164^{*}$ & $-0.6529^{*}$ & $(0.2202)$ \\
& $(0.0086)$ & $(0.3786)$ & -0.0033 \\
High cost mandates $\times$ & 0.0001 & $0.0423^{*}$ & $(0.0078)$ \\
potential experience & $(0.0005)$ & $(0.0222)$ & 80,012 \\
\hline Unweighted observations & 78,838 & 76,596 &
\end{tabular}

Notes: All models estimated with least squares and control for demographics, labor market entrance state fixed effects, and labor market entrance year fixed effects. NLSY79 sample weights applied. Standard errors are clustered around the labor market entrance state and reported in parentheses.

${ }^{1} \mathrm{ESI}=$ Employer-sponsored health insurance offer.

$* * * ; * ; *=$ statistically different from zero at the $1 \% ; 5 \% ; 10 \%$ level.

Supplementary Appendix Table 2: The persistent effect of high cost mandates at labor market entrance on labor market outcomes using the sample with complete information on all outcome variables: NLSY79 19792012

\begin{tabular}{|c|c|c|c|c|}
\hline Outcome: & ESI $^{1}$ & Log(wages) & Log(weeks) & Full-time \\
\hline \multicolumn{5}{|l|}{ Male sample } \\
\hline Sample proportion/mean & 0.799 & 22.91 & 45.32 & 0.934 \\
\hline High cost mandates & $\begin{array}{l}-0.0121 \\
(0.0084)\end{array}$ & $\begin{array}{c}-0.0313 * * \\
(0.0147)\end{array}$ & $\begin{array}{l}-0.0089 \\
(0.0065)\end{array}$ & $\begin{array}{c}-0.0126 * * * \\
(0.0036)\end{array}$ \\
\hline $\begin{array}{l}\text { High cost mandates } \times \\
\text { potential experience }\end{array}$ & $\begin{array}{c}0.0004 \\
(0.0003) \\
\end{array}$ & $\begin{array}{c}0.0027 * * * \\
(0.0008)\end{array}$ & $\begin{array}{l}0.0007 * * \\
(0.0003) \\
\end{array}$ & $\begin{array}{c}0.0011 * * * \\
(0.0002)\end{array}$ \\
\hline Unweighted observations & 64,097 & 64,097 & 64,097 & 64,097 \\
\hline \multicolumn{5}{|l|}{ Female sample } \\
\hline Sample proportion/mean & 0.772 & 17.50 & 39.51 & 0.798 \\
\hline High cost mandates & $\begin{array}{l}-0.0100 \\
(0.0072)\end{array}$ & $\begin{array}{c}-0.0318 * * * \\
(0.0104)\end{array}$ & $\begin{array}{l}-0.0008 \\
(0.0077)\end{array}$ & $\begin{array}{c}-0.0179 * * * \\
(0.0058)\end{array}$ \\
\hline $\begin{array}{l}\text { High cost mandates } \times \\
\text { potential experience }\end{array}$ & $\begin{array}{c}0.0005 \\
(0.0004) \\
\end{array}$ & $\begin{array}{c}0.0021 * * * \\
(0.0005)\end{array}$ & $\begin{array}{c}0.0002 \\
(0.0003) \\
\end{array}$ & $\begin{array}{c}0.0006 \\
(0.0004) \\
\end{array}$ \\
\hline Unweighted observations & 59,622 & 59,622 & 59,622 & 59,622 \\
\hline
\end{tabular}

Notes: All models are estimated with least squares (continuous variables) or a linear probability model (binary variables) and control for demographics, labor market entrance state fixed effects, and labor market entrance year fixed effects. NLSY79 sample weights applied. Standard errors are clustered around the labor market entrance state and reported in parentheses.

${ }^{1} \mathrm{ESI}=$ Employer-sponsored health insurance offer.

$* * * * * ; *=$ statistically different from zero at the $1 \% ; 5 \% ; 10 \%$ level. 
Supplementary Appendix Table 3A: The persistent effect of high cost mandates at labor market entrance on labor market outcomes using alternative approaches to proxying labor market entrance state: NLSY79 men 1979-2012

\begin{tabular}{lcccc}
\hline Outcome: & ESI $^{\mathbf{1}}$ & Log(wages) & Log(weeks) & Full-time \\
\hline State of residence at age 14 & & & & \\
\hline Sample proportion/mean & 0.790 & 22.08 & 46.11 & 0.897 \\
\hline High cost mandates & -0.0108 & $-0.0459^{* *}$ & -0.0105 & $-0.0214^{* * *}$ \\
& $(0.0098)$ & $(0.0189)$ & $(0.0077)$ & $(0.0078)$ \\
High cost mandates $\times$ & 0.0005 & $0.0037^{* * *}$ & $0.0013^{* * *}$ & $0.0017^{* * *}$ \\
potential experience & $(0.0004)$ & $(0.0010)$ & $(0.0004)$ & $(0.0003)$ \\
\hline Unweighted observations & 68,464 & 79,806 & 83,489 & 82,179 \\
\hline State of residence in 1979 & & & & \\
\hline Sample proportion/mean & 0.790 & 22.08 & 46.11 & 0.897 \\
\hline High cost mandates & -0.0101 & $-0.0419^{* *}$ & -0.0101 & $-0.0221^{* * *}$ \\
& $(0.0098)$ & $(0.0176)$ & $(0.0077)$ & $(0.0072)$ \\
High cost mandates $\times$ & 0.0005 & $0.0035^{* * *}$ & $0.0012^{* * *}$ & $0.0017^{* * *}$ \\
potential experience & $(0.0004)$ & $(0.0009)$ & $(0.0004)$ & $(0.0003)$ \\
\hline Unweighted observations & 68,464 & 79,806 & 83,489 & 82,179
\end{tabular}

Notes: All models are estimated with least squares (continuous variables) or a linear probability model (binary variables) and control for demographics, labor market entrance state fixed effects, and labor market entrance year fixed effects. NLSY79 sample weights applied. Standard errors are clustered around the labor market entrance state and reported in parentheses.

${ }^{1} \mathrm{ESI}=$ Employer-sponsored health insurance offer.

$* * * ; * ; *=$ statistically different from zero at the $1 \% ; 5 \% ; 10 \%$ level.

Supplementary Appendix Table 3B: The persistent effect of high cost mandates at labor market entrance on labor market outcomes using alternative approaches to proxying labor market entrance state: NLSY79 women 1979-2012

\begin{tabular}{lcccc}
\hline \hline Outcome: & ESI $^{\mathbf{1}}$ & Log(wages) & \multicolumn{1}{l}{ Log(weeks) } & Full-time \\
\hline State of residence at age 14 & & & & \\
\hline Sample proportion/mean & 0.790 & 22.08 & 46.11 & 0.897 \\
\hline High cost mandates & -0.0144 & $-0.0372^{* * *}$ & 0.0114 & $-0.0231^{* *}$ \\
& $(0.0088)$ & $(0.0081)$ & $(0.0094)$ & $(0.0088)$ \\
High cost mandates $\times$ & 0.0004 & $0.0024^{* * *}$ & -0.0005 & $0.0009^{* *}$ \\
potential experience & $(0.0004)$ & $(0.0006)$ & $(0.0004)$ & $(0.0004)$ \\
\hline Unweighted observations & 64,163 & 76,596 & 80,012 & 78,855 \\
\hline State of residence in 1979 & & & & \\
\hline Sample proportion/mean & 0.790 & 22.08 & 46.11 & 0.897 \\
\hline High cost mandates & -0.0162 & $-0.0326^{* * *}$ & 0.0104 & $-0.0244^{* *}$ \\
& $(0.0099)$ & $(0.0100)$ & $(0.0087)$ & $(0.0093)$ \\
High cost mandates $\times$ & 0.0006 & $0.0024^{* * *}$ & -0.0004 & $0.0009^{* *}$ \\
potential experience & $(0.0004)$ & $(0.0006)$ & $(0.0003)$ & $0.0004)$ \\
\hline Unweighted observations & 64,163 & 76,596 & 80,012 & 78,855 \\
\hline
\end{tabular}

Notes: All models are estimated with least squares (continuous variables) or a linear probability model (binary variables) and control for demographics, labor market entrance state fixed effects, and labor market entrance year fixed effects. NLSY79 sample weights applied. Standard errors are clustered around the labor market entrance state and reported in parentheses.

${ }^{1} \mathrm{ESI}=$ Employer-sponsored health insurance offer.

$* * * ; * ; *=$ statistically different from zero at the $1 \% ; 5 \% ; 10 \%$ level. 
Supplementary Appendix Table 4: The persistent effect of high cost mandates at labor market entrance on labor market outcomes including pre-1973 school-leavers: NLSY79 1979-2012

\begin{tabular}{|c|c|c|c|c|}
\hline Outcome: & ESI $^{1}$ & Log(wages) & Log(weeks) & Full-time \\
\hline \multicolumn{5}{|l|}{ Male sample } \\
\hline Sample proportion/mean & 0.789 & 22.08 & 46.10 & 0.896 \\
\hline High cost mandates & $\begin{array}{l}-0.0123 \\
(0.0080)\end{array}$ & $\begin{array}{c}-0.0393 * * \\
(0.0150)\end{array}$ & $\begin{array}{c}-0.0165 * * \\
(0.0073)\end{array}$ & $\begin{array}{c}-0.0230 * * * \\
(0.0051)\end{array}$ \\
\hline $\begin{array}{l}\text { High cost mandates } \times \\
\text { potential experience }\end{array}$ & $\begin{array}{c}0.0005 \\
(0.0003)\end{array}$ & $\begin{array}{c}0.0032 * * * \\
(0.0008)\end{array}$ & $\begin{array}{c}0.0013 * * * \\
(0.0004)\end{array}$ & $\begin{array}{c}0.0018 * * * \\
(0.0003)\end{array}$ \\
\hline Unweighted observations & 68,643 & 80,048 & 83,758 & 82,443 \\
\hline \multicolumn{5}{|l|}{ Female sample } \\
\hline Sample proportion/mean & 0.761 & 16.66 & 43.93 & 0.725 \\
\hline High cost mandates & $\begin{array}{l}-0.0116 \\
(0.0074)\end{array}$ & $\begin{array}{c}-0.0267 * * * \\
(0.0091)\end{array}$ & $\begin{array}{c}0.0018 \\
(0.0089)\end{array}$ & $\begin{array}{c}-0.0240 * * * \\
(0.0072)\end{array}$ \\
\hline $\begin{array}{l}\text { High cost mandates } \times \\
\text { potential experience }\end{array}$ & $\begin{array}{c}0.0005 \\
(0.0004)\end{array}$ & $\begin{array}{c}0.0022 * * * \\
(0.0005)\end{array}$ & $\begin{array}{l}-0.0004 \\
(0.0003)\end{array}$ & $\begin{array}{l}0.0007^{*} \\
(0.0004)\end{array}$ \\
\hline Unweighted observations & 64,472 & 76,974 & 80,407 & 79,238 \\
\hline
\end{tabular}

Notes: All models are estimated with least squares (continuous variables) or a linear probability model (binary variables) and control for demographics, labor market entrance state fixed effects, and labor market entrance year fixed effects. Regressions do not include the labor market entrance poverty rate variable as the CPS does not provide this variable for all labor market entrance years in our sample. More details available on request from the corresponding author. NLSY79 sample weights applied. Standard errors are clustered around the labor market entrance state and reported in parentheses.

${ }^{1} \mathrm{ESI}=$ Employer-sponsored health insurance offer.

$* * * ; * ; *=$ statistically different from zero at the $1 \% ; 5 \% ; 10 \%$ level.

Supplementary Appendix Table 5: The persistent effect of high cost mandates at labor market entrance on labor market outcomes excluding 1973: NLSY79 1979-2012

\begin{tabular}{|c|c|c|c|c|}
\hline Outcome: & ESI $^{1}$ & Log(wages) & Log(weeks) & Full-time \\
\hline \multicolumn{5}{|l|}{ Male sample } \\
\hline Baseline proportion/mean & 0.764 & 20.11 & 44.87 & 0.884 \\
\hline High cost mandates & $\begin{array}{l}-0.0124 \\
(0.0080)\end{array}$ & $\begin{array}{c}-0.0388 * * \\
(0.0155)\end{array}$ & $\begin{array}{l}-0.0144^{*} \\
(0.0078)\end{array}$ & $\begin{array}{c}-0.0219 * * * \\
(0.0054)\end{array}$ \\
\hline $\begin{array}{l}\text { High cost mandates } \times \\
\text { potential experience }\end{array}$ & $\begin{array}{c}0.0005 \\
(0.0003) \\
\end{array}$ & $\begin{array}{c}0.0032 * * * \\
(0.0008)\end{array}$ & $\begin{array}{c}0.0012 * * * \\
(0.0004)\end{array}$ & $\begin{array}{c}0.0018 * * * \\
(0.0003)\end{array}$ \\
\hline Unweighted observations & 68,101 & 79,332 & 83,001 & 81,697 \\
\hline \multicolumn{5}{|l|}{ Female sample } \\
\hline Baseline proportion/mean & 0.762 & 16.71 & 37.60 & 0.724 \\
\hline High cost mandates & $\begin{array}{l}-0.0124 \\
(0.0075)\end{array}$ & $\begin{array}{c}-0.0262 * * * \\
(0.0088)\end{array}$ & $\begin{array}{c}0.0028 \\
(0.0088)\end{array}$ & $\begin{array}{c}-0.0232 * * * \\
(0.0075)\end{array}$ \\
\hline $\begin{array}{l}\text { High cost mandates } \times \\
\text { potential experience }\end{array}$ & $\begin{array}{c}0.0004 \\
(0.0004) \\
\end{array}$ & $\begin{array}{c}0.0022 * * * \\
(0.0005)\end{array}$ & $\begin{array}{l}-0.0004 \\
(0.0003)\end{array}$ & $\begin{array}{l}0.0007 * \\
(0.0004)\end{array}$ \\
\hline Unweighted observations & 63,774 & 76,096 & 79,484 & 78,335 \\
\hline
\end{tabular}

Notes: All models are estimated with least squares (continuous variables) or a linear probability model (binary variables) and control for demographics, labor market entrance state fixed effects, and labor market entrance year fixed effects. NLSY79 sample weights applied. Standard errors are clustered around the labor market entrance state and reported in parentheses.

${ }^{1} \mathrm{ESI}=$ Employer-sponsored health insurance offer.

$* * * ; * * * *=$ statistically different from zero at the $1 \% ; 5 \% ; 10 \%$ level. 
Supplementary Appendix Table 6. The persistent effect of high cost mandates at labor market entrance on labor market outcomes excluding continuing coverage mandate from high cost mandates variable: NLSY79 1979-2012

\begin{tabular}{|c|c|c|c|c|}
\hline Outcome: & ESI $^{1}$ & Log(wages) & Log(weeks) & Full-time \\
\hline \multicolumn{5}{|l|}{ Male sample } \\
\hline Sample proportion/mean & 0.790 & 22.08 & 46.11 & 0.897 \\
\hline \multirow[t]{2}{*}{ High cost mandates } & -0.0126 & $-0.0348 * *$ & $-0.0190 * *$ & $-0.0218 * * *$ \\
\hline & $(0.0100)$ & $(0.0167)$ & $(0.0087)$ & $(0.0059)$ \\
\hline High cost mandates $\times$ & 0.0006 & $0.0029 * * *$ & $0.0014 * * *$ & $0.0017 * * *$ \\
\hline potential experience & $(0.0004)$ & $(0.0010)$ & $(0.0004)$ & $(0.0003)$ \\
\hline Unweighted observations & 68,464 & 79,806 & 83,489 & 82,179 \\
\hline \multicolumn{5}{|l|}{ Female sample } \\
\hline Sample proportion/mean & 0.761 & 16.68 & 43.95 & 0.724 \\
\hline \multirow[t]{2}{*}{ High cost mandates } & $-0.0149 * *$ & -0.0152 & 0.0040 & $-0.0231 * * *$ \\
\hline & $(0.0067)$ & $(0.0106)$ & $(0.0082)$ & $(0.0076)$ \\
\hline High cost mandates $x$ & $0.0007 *$ & $0.0021 * * *$ & -0.0003 & 0.0007 \\
\hline potential experience & $(0.0004)$ & $(0.0006)$ & $(0.0003)$ & $(0.0005)$ \\
\hline Unweighted observations & 64,163 & 76,596 & 80,012 & 78,855 \\
\hline
\end{tabular}

Notes: All models are estimated with least squares (continuous variables) or a linear probability model (binary variables) and control for demographics, labor market entrance state fixed effects, and labor market entrance year fixed effects. NLSY79 sample weights applied. Standard errors are clustered around the labor market entrance state and reported in parentheses.

${ }^{1} \mathrm{ESI}=$ Employer-sponsored health insurance offer.

$* * * ; * ; *=$ statistically different from zero at the $1 \% ; 5 \% ; 10 \%$ level.

Supplementary Appendix Table 7. The persistent effect of high cost mandates at labor market entrance on labor market outcomes excluding observations with missing control variables: NLSY79 1979-2012

\begin{tabular}{|c|c|c|c|c|}
\hline Outcome: & ESI $^{1}$ & Log(wages) & Log(weeks) & Full-time \\
\hline \multicolumn{5}{|l|}{ Male sample } \\
\hline Sample proportion/mean & 0.799 & 22.63 & 44.82 & 0.898 \\
\hline High cost mandates & $\begin{array}{l}-0.0132 \\
(0.0083)\end{array}$ & $\begin{array}{c}-0.0377 * * \\
(0.0153)\end{array}$ & $\begin{array}{l}-0.0178 * \\
(0.0096)\end{array}$ & $\begin{array}{c}-0.0226 * * * \\
(0.0063)\end{array}$ \\
\hline $\begin{array}{l}\text { High cost mandates } \times \\
\text { potential experience }\end{array}$ & $\begin{array}{c}0.0004 \\
(0.0004) \\
\end{array}$ & $\begin{array}{c}0.0028 * * * \\
(0.0008)\end{array}$ & $\begin{array}{c}0.0012 * * * \\
(0.0004) \\
\end{array}$ & $\begin{array}{c}0.0018 * * * \\
(0.0003) \\
\end{array}$ \\
\hline Unweighted observations & 57,019 & 66,179 & 69,244 & 68,163 \\
\hline \multicolumn{5}{|l|}{ Female sample } \\
\hline Sample proportion/mean & 0.771 & 16.95 & 37.55 & 0.723 \\
\hline High cost mandates & $\begin{array}{c}-0.0135^{*} \\
(0.0074)\end{array}$ & $\begin{array}{c}-0.0327 * * * \\
(0.0079)\end{array}$ & $\begin{array}{c}0.0001 \\
(0.0081)\end{array}$ & $\begin{array}{c}-0.0267 * * * \\
(0.0075)\end{array}$ \\
\hline $\begin{array}{l}\text { High cost mandates } \times \\
\text { potential experience }\end{array}$ & $\begin{array}{c}0.0004 \\
(0.0004) \\
\end{array}$ & $\begin{array}{c}0.0022 * * * \\
(0.0006)\end{array}$ & $\begin{array}{l}-0.0003 \\
(0.0003) \\
\end{array}$ & $\begin{array}{c}0.0008 \\
(0.0005) \\
\end{array}$ \\
\hline Unweighted observations & 54,159 & 64,558 & 67,506 & 66,536 \\
\hline
\end{tabular}

Notes: All models are estimated with least squares (continuous variables) or a linear probability model (binary variables) and control for demographics, labor market entrance state fixed effects, and labor market entrance year fixed effects. NLSY79 sample weights applied. Standard errors are clustered around the labor market entrance state and reported in parentheses.

${ }^{1} \mathrm{ESI}=$ Employer-sponsored health insurance offer.

$* * * ; * ; *=$ statistically different from zero at the $1 \% ; 5 \% ; 10 \%$ level. 
Supplementary Appendix Table 8. The persistent effect of high cost mandates at labor market entrance on labor market outcomes excluding time-varying state-level controls from regression model: NLSY79 1979-

2012

\begin{tabular}{lcccc}
\hline \hline Outcome: & ESI $^{\mathbf{1}}$ & Log(wages) & \multicolumn{1}{l}{ Log(weeks) } & Full-time \\
\hline Male sample & & & & \\
\hline Sample proportion/mean & 0.790 & 22.08 & 46.11 & 0.897 \\
\hline High cost mandates & $-0.0151^{*}$ & $-0.0375^{* *}$ & $-0.0175^{* *}$ & $-0.0226^{* * *}$ \\
& $(0.0086)$ & $(0.0152)$ & $(0.0077)$ & $(0.0051)$ \\
High cost mandates $\times$ & 0.0006 & $0.0032^{* * *}$ & $0.0013^{* * *}$ & $0.0018^{* * *}$ \\
potential experience & $(0.0003)$ & $(0.0008)$ & $(0.0004)$ & $(0.0003)$ \\
\hline Unweighted observations & 68,464 & 79,806 & 83,489 & 82,179 \\
\hline Female sample & & & & \\
\hline Sample proportion/mean & 0.761 & 16.68 & 43.95 & 0.724 \\
\hline High cost mandates & -0.0133 & $-0.0264^{* * *}$ & 0.0010 & $-0.0223^{* * *}$ \\
& $(0.0079)$ & $(0.0097)$ & $(0.0091)$ & $(0.0076)$ \\
High cost mandates $\times$ & 0.0005 & $0.0022^{* * *}$ & -0.0004 & 0.0007 \\
potential experience & $(0.0004)$ & $(0.0005)$ & $(0.0003)$ & $0.0004)$ \\
\hline Unweighted observations & 64,163 & 76,596 & 80,012 & 78,855 \\
\hline
\end{tabular}

Notes: All models are estimated with least squares (continuous variables) or a linear probability model (binary variables) and control for demographics, labor market entrance state fixed effects, and labor market entrance year fixed effects. NLSY79 sample weights applied. Standard errors are clustered around the labor market entrance state and reported in parentheses.

${ }^{1} \mathrm{ESI}=$ Employer-sponsored health insurance offer.

$* * * ; * ; *=$ statistically different from zero at the $1 \% ; 5 \% ; 10 \%$ level.

Supplementary Appendix Table 9. The persistent effect of high cost mandates at labor market entrance on labor market outcomes without lagging the mandate variables by one year: NLSY79 1979-2012

\begin{tabular}{lcccc}
\hline \hline Outcome: & ESI $^{\mathbf{1}}$ & Log(wages) & Log(weeks) & Full-time \\
\hline Male sample & & & & \\
\hline Sample proportion/mean & 0.790 & 22.08 & 46.11 & 0.897 \\
\hline High cost mandates & -0.0117 & $-0.0428^{* * *}$ & -0.0104 & $-0.0237^{* * *}$ \\
& $(0.0086)$ & $(0.0147)$ & $(0.0094)$ & $(0.0059)$ \\
High cost mandates & 0.0005 & $0.0027^{* * *}$ & $0.0010^{* * *}$ & $0.0018^{* * *}$ \\
potential experience & $(0.0003)$ & $(0.0007)$ & $(0.0004)$ & $(0.0003)$ \\
\hline Unweighted observations & 68,464 & 79,806 & 83,489 & 82,179 \\
\hline Female sample & & & & \\
\hline Sample proportion/mean & 0.761 & 16.68 & 43.95 & 0.724 \\
\hline High cost mandates & -0.0071 & -0.0159 & -0.0044 & $-0.0158^{* *}$ \\
& $(0.0077)$ & $(0.0121)$ & $(0.0080)$ & $(0.0073)$ \\
High cost mandates $\times$ & 0.0005 & $0.0021^{* * *}$ & -0.0002 & $0.0008^{*}$ \\
potential experience & $(0.0004)$ & $(0.0005)$ & $(0.0003)$ & $0.0004)$ \\
\hline Unweighted observations & 64,163 & 76,596 & 80,012 & 78,855 \\
\hline
\end{tabular}

Notes: All models are estimated with least squares (continuous variables) or a linear probability model (binary variables) and control for demographics, labor market entrance state fixed effects, and labor market entrance year fixed effects. NLSY79 sample weights applied. Standard errors are clustered around the labor market entrance state and reported in parentheses.

${ }^{1} \mathrm{ESI}=$ Employer-sponsored health insurance offer.

$* * * ; * ; *=$ statistically different from zero at the $1 \% ; 5 \% ; 10 \%$ level. 
Supplementary Appendix Table 10. The persistent effect of high cost mandates at labor market entrance on labor market excluding individual-level controls from the regression model: NLSY79 1979-2012

\begin{tabular}{lcccc}
\hline \hline Outcome: & ESI $^{\mathbf{1}}$ & Log(wages) & \multicolumn{1}{l}{ Log(weeks) } & Full-time \\
\hline Male sample & & & & \\
\hline Sample proportion/mean & 0.790 & 22.08 & 46.11 & 0.897 \\
\hline High cost mandates & $-0.0188^{* *}$ & $-0.0464^{* * *}$ & $-0.0227^{* * *}$ & $-0.0239^{* * *}$ \\
& $(0.0089)$ & $(0.0162)$ & $(0.0084)$ & $(0.0054)$ \\
High cost mandates $\times$ & 0.0005 & $0.0031^{* * *}$ & $0.0013^{* * *}$ & $0.0018^{* * *}$ \\
potential experience & $(0.0003)$ & $(0.0008)$ & $(0.0004)$ & $(0.0003)$ \\
\hline Unweighted observations & 68,464 & 79,806 & 83,489 & 82,179 \\
\hline Female sample & & & & \\
\hline Sample proportion/mean & 0.761 & 16.68 & 43.95 & 0.724 \\
\hline High cost mandates & $-0.0162^{*}$ & $-0.0413^{* * *}$ & -0.0014 & $-0.0239^{* * *}$ \\
& $(0.0083)$ & $(0.0113)$ & $(0.0086)$ & $0.0071)$ \\
High cost mandates $\times$ & 0.0005 & $0.0022^{* * *}$ & -0.0003 & $0.0008^{*}$ \\
potential experience & $(0.0004)$ & $(0.0006)$ & $(0.0003)$ & $(0.0004)$ \\
\hline Unweighted observations & 64,163 & 76,596 & 80,012 & 78,855 \\
\hline
\end{tabular}

Notes: All models are estimated with least squares (continuous variables) or a linear probability model (binary variables) and control for demographics, labor market entrance state fixed effects, and labor market entrance year fixed effects. NLSY79 sample weights applied. Standard errors are clustered around the labor market entrance state and reported in parentheses.

${ }^{1}$ ESI=Employer-sponsored health insurance offer.

$* * * * * ; *=$ statistically different from zero at the $1 \% ; 5 \% ; 10 \%$ level. 
Supplementary Appendix Table 11A. The persistent effect of high cost mandates at labor market entrance on labor market outcomes using different controls for between-state differences: NLSY79 men 1979-2012

\begin{tabular}{|c|c|c|c|c|}
\hline Outcome: & ESI $^{1}$ & Log(wages) & Log(weeks) & Full-time \\
\hline Sample proportion/mean & 0.790 & 22.08 & 46.11 & 0.897 \\
\hline \multicolumn{5}{|l|}{$\begin{array}{l}\text { Include state-specific linear } \\
\text { trends }\end{array}$} \\
\hline High cost mandates & $\begin{array}{l}-0.0058 \\
(0.0105)\end{array}$ & $\begin{array}{c}-0.0428 * * \\
(0.0207)\end{array}$ & $\begin{array}{l}-0.0161^{*} \\
(0.0094)\end{array}$ & $\begin{array}{c}-0.0235 * * * \\
(0.0034)\end{array}$ \\
\hline $\begin{array}{l}\text { High cost mandates } \times \\
\text { potential experience }\end{array}$ & $\begin{array}{c}0.0004 \\
(0.0003)\end{array}$ & $\begin{array}{c}0.0033 * * * \\
(0.0008)\end{array}$ & $\begin{array}{c}0.0012 * * * \\
(0.0004)\end{array}$ & $\begin{array}{c}0.0018 * * * \\
(0.0003)\end{array}$ \\
\hline \multicolumn{5}{|l|}{$\begin{array}{l}\text { Include state-specific } \\
\text { quadratic trends }\end{array}$} \\
\hline High cost mandates & $\begin{array}{c}0.0005 \\
(0.0110)\end{array}$ & $\begin{array}{l}-0.0242 \\
(0.0237)\end{array}$ & $\begin{array}{l}-0.0127 \\
(0.0091)\end{array}$ & $\begin{array}{c}-0.0194 * * * \\
(0.0043)\end{array}$ \\
\hline $\begin{array}{l}\text { High cost mandates } \times \\
\text { potential experience }\end{array}$ & $\begin{array}{c}0.0005 \\
(0.0003) \\
\end{array}$ & $\begin{array}{c}0.0033 * * * \\
(0.0008)\end{array}$ & $\begin{array}{c}0.0012 * * * \\
(0.0004)\end{array}$ & $\begin{array}{r}0.0018^{* * *} \\
(0.0003) \\
\end{array}$ \\
\hline \multicolumn{5}{|l|}{$\begin{array}{l}\text { Include current state fixed } \\
\text { effects }\end{array}$} \\
\hline High cost mandates & $\begin{array}{l}-0.0117 \\
(0.0080)\end{array}$ & $\begin{array}{c}-0.0376^{* *} \\
(0.0147)\end{array}$ & $\begin{array}{l}-0.0157^{*} \\
(0.0080)\end{array}$ & $\begin{array}{c}-0.0223 * * * \\
(0.0056)\end{array}$ \\
\hline $\begin{array}{l}\text { High cost mandates } \times \\
\text { potential experience }\end{array}$ & $\begin{array}{c}0.0005 \\
(0.0003)\end{array}$ & $\begin{array}{c}0.0032 * * * \\
(0.0008)\end{array}$ & $\begin{array}{c}0.0013 * * * \\
(0.0004)\end{array}$ & $\begin{array}{c}0.0018^{* * *} \\
(0.0003)\end{array}$ \\
\hline Unweighted observations & 68,464 & 79,806 & 83,489 & 82,179 \\
\hline
\end{tabular}

Notes: All models are estimated with least squares (continuous variables) or a linear probability model (binary variables) and control for demographics, labor market entrance state fixed effects, and labor market entrance year fixed effects. NLSY79 sample weights applied. Standard errors are clustered around the labor market entrance state and reported in parentheses.

${ }^{1}$ ESI=Employer-sponsored health insurance offer.

$* * * * * ; *=$ statistically different from zero at the $1 \% ; 5 \% ; 10 \%$ level. 
Supplementary Appendix Table 11B. The persistent effect of high cost mandates at labor market entrance on labor market outcomes using different controls for between-state differences: NLSY79 men 1979-2012

\begin{tabular}{lcccc}
\hline \hline Outcome: & ESI $^{\mathbf{1}}$ & Log(wages) & Log(weeks) & Full-time \\
\hline Sample proportion/mean & 0.761 & 16.68 & 43.95 & 0.724 \\
\hline $\begin{array}{l}\text { Include state-specific linear } \\
\text { trends }\end{array}$ & & & \\
\hline High cost mandates & -0.0126 & $-0.0391^{* * *}$ & 0.0026 & $-0.0272^{* * *}$ \\
& $(0.0092)$ & $(0.0126)$ & $(0.0112)$ & $(0.0078)$ \\
High cost mandates $\times$ & 0.0005 & $0.0022^{* * *}$ & -0.0003 & $0.0008^{*}$ \\
potential experience & $(0.0004)$ & $(0.0005)$ & $(0.0003)$ & $(0.0004)$ \\
\hline Include state-specific & & & & \\
quadratic trends & & & 0.0042 & $-0.0190^{* *}$ \\
\hline High cost mandates & $-0.0209^{*}$ & $-0.0429^{* * *}$ & $(0.0112)$ & $0.0094)$ \\
& $(0.0111)$ & $(0.0118)$ & -0.0004 & $0.0008^{*}$ \\
High cost mandates $\times$ & 0.0005 & $0.0022^{* * *}$ & $(0.0003)$ & $(0.0004)$ \\
potential experience & $(0.0004)$ & $(0.0005)$ & & \\
\hline Include current state fixed & & & & \\
effects & & & 0.0017 & $\left(0.0224^{* * *}\right.$ \\
\hline High cost mandates & -0.0114 & $-0.0290^{* * *}$ & $(0.0088)$ & 0.0007 \\
& $(0.0072)$ & $(0.0088)$ & -0.0004 & $(0.0005)$ \\
High cost mandates $\times$ & 0.0004 & $0.0022^{* * *}$ & $(0.0003)$ & 78,855 \\
potential experience & $(0.0004)$ & $(0.0005)$ & 80,012 & \\
\hline Unweighted observations & 64,163 & 76,596 & & \\
\hline Notes: All & & & & \\
\end{tabular}

Notes: All models are estimated with least squares (continuous variables) or a linear probability model (binary variables) and control for demographics, labor market entrance state fixed effects, and labor market entrance year fixed effects. NLSY79 sample weights applied. Standard errors are clustered around the labor market entrance state and reported in parentheses.

${ }^{1}$ ESI=Employer-sponsored health insurance offer.

$* * * * * ; *=$ statistically different from zero at the $1 \% ; 5 \% ; 10 \%$ level. 
Supplementary Appendix Table 12. The persistent effect of high cost mandates at labor market entrance on labor market removing survey weights: NLSY79 1979-2012

\begin{tabular}{lcccc}
\hline \hline Outcome: & ESI $^{\mathbf{1}}$ & Log(wages) & Log(weeks) & Full-time \\
\hline Male sample & & & & \\
\hline $\begin{array}{l}\text { Unweighted sample } \\
\text { proportion/mean }\end{array}$ & 0.763 & 20.07 & 43.95 & 0.884 \\
\hline High cost mandates & -0.0099 & $-0.0487^{* * *}$ & $-0.0110^{*}$ & $-0.0281^{* * *}$ \\
& $(0.0066)$ & $(0.0151)$ & $(0.0064)$ & $(0.0050)$ \\
High cost mandates & $0.0005^{*}$ & $0.0035^{* * *}$ & $0.0013^{* * *}$ & $0.0019^{* * *}$ \\
potential experience & $(0.0003)$ & $(0.0008)$ & $(0.0003)$ & $(0.0003)$ \\
\hline Unweighted observations & 68,464 & 79,806 & 83,489 & 82,179 \\
\hline Female sample & & & & \\
\hline Unweighted sample & 0.752 & 15.77 & 37.80 & 0.734 \\
proportion/mean & & & 0.0048 & $-0.0207^{* * *}$ \\
\hline High cost mandates & $-0.0167^{* *}$ & $-0.0268^{* *}$ & $(0.0104)$ & $(0.0057)$ \\
& $(0.0073)$ & $(0.0105)$ & $-0.0007^{* *}$ & $0.0009^{* *}$ \\
High cost mandates $\times$ & $0.0006^{*}$ & $0.0025^{* * *}$ & $(0.0003)$ & $(0.0004)$ \\
potential experience & $(0.0003)$ & $(0.0004)$ & 80,012 & 78,855 \\
\hline Unweighted observations & 64,163 & 76,596 & & \\
\hline
\end{tabular}

Notes: All models are estimated with least squares (continuous variables) or a linear probability model (binary variables) and control for demographics, labor market entrance state fixed effects, and labor market entrance year fixed effects. Standard errors are clustered around the labor market entrance state and reported in parentheses. ${ }^{1} \mathrm{ESI}=$ Employer-sponsored health insurance offer. $* * * ; * ; *=$ statistically different from zero at the $1 \% ; 5 \% ; 10 \%$ level. 
Supplementary Appendix Table 13A. The persistent effect of high cost mandates at labor market entrance on labor market outcomes showing all coefficient estimates: NLSY79 men 1979-2012

\begin{tabular}{|c|c|c|c|c|}
\hline Outcome: & ESI $^{1}$ & Log(wages) & Log(weeks) & Full-time \\
\hline Sample proportion/mean & 0.790 & 22.08 & 46.11 & 0.897 \\
\hline High cost mandates & $\begin{array}{l}-0.0133 \\
(0.0080)\end{array}$ & $\begin{array}{c}-0.0399 * * \\
(0.0154)\end{array}$ & $\begin{array}{c}-0.0165 * * \\
(0.0081)\end{array}$ & $\begin{array}{c}-0.0226 * * * \\
(0.0054)\end{array}$ \\
\hline $\begin{array}{l}\text { High cost mandates } \times \\
\text { potential experience }\end{array}$ & $\begin{array}{l}0.0005 \\
(0.0003)\end{array}$ & $\begin{array}{c}0.0032 * * * \\
(0.0008)\end{array}$ & $\begin{array}{c}0.0013 * * * \\
(0.0004)\end{array}$ & $\begin{array}{c}0.0018^{* * *} \\
(0.0003)\end{array}$ \\
\hline Potential experience & $\begin{array}{c}0.0064 * * * \\
(0.0008)\end{array}$ & $\begin{array}{c}0.0138^{* * * *} \\
(0.0016)\end{array}$ & $\begin{array}{c}0.0104 * * * \\
(0.0009)\end{array}$ & $\begin{array}{c}0.0037 * * * \\
(0.0005)\end{array}$ \\
\hline \multicolumn{5}{|l|}{ Personal characteristics } \\
\hline $\begin{array}{l}\text { Age at labor market } \\
\text { entrance }\end{array}$ & $\begin{array}{l}0.0050 * * \\
(0.0025)\end{array}$ & $\begin{array}{c}0.0099 \\
(0.0063)\end{array}$ & $\begin{array}{c}0.0075 * * * \\
(0.0023)\end{array}$ & $\begin{array}{c}0.0026 \\
(0.0018)\end{array}$ \\
\hline $\begin{array}{l}\text { High school at labor market } \\
\text { entrance }\end{array}$ & $\begin{array}{c}0.1493 * * * \\
(0.0109)\end{array}$ & $\begin{array}{c}0.1150^{* * * *} \\
(0.0157)\end{array}$ & $\begin{array}{c}0.1135^{* * *} \\
(0.0105)\end{array}$ & $\begin{array}{c}0.0246 * * * \\
(0.0064)\end{array}$ \\
\hline $\begin{array}{l}\text { Some college at labor market } \\
\text { entrance }\end{array}$ & $\begin{array}{c}0.1598 * * * \\
(0.0175)\end{array}$ & $\begin{array}{c}0.1774 * * * \\
(0.0306)\end{array}$ & $\begin{array}{l}0.1315^{* * * *} \\
(0.0124)\end{array}$ & $\begin{array}{c}0.0151 \\
(0.0093)\end{array}$ \\
\hline $\begin{array}{l}\text { College at labor market } \\
\text { entrance }\end{array}$ & $\begin{array}{l}0.2088 * * * \\
(0.0184)\end{array}$ & $\begin{array}{c}0.4258 * * * \\
(0.0410)\end{array}$ & $\begin{array}{c}0.1501 * * * \\
(0.0147)\end{array}$ & $\begin{array}{c}0.0509 * * * \\
(0.0101)\end{array}$ \\
\hline African American & $\begin{array}{l}-0.0221 \\
(0.0139)\end{array}$ & $\begin{array}{c}-0.1040^{* * *} \\
(0.0164)\end{array}$ & $\begin{array}{c}-0.1097 * * * \\
(0.0091)\end{array}$ & $\begin{array}{c}-0.0384 * * * \\
(0.0073)\end{array}$ \\
\hline Hispanic & $\begin{array}{c}0.0209 \\
(0.0186)\end{array}$ & $\begin{array}{l}0.0163 \\
(0.0297)\end{array}$ & $\begin{array}{l}-0.0167 \\
(0.0171)\end{array}$ & $\begin{array}{l}-0.0084^{*} \\
(0.0047)\end{array}$ \\
\hline $\begin{array}{l}\text { Age-adjusted AFQT } \\
\text { score }\end{array}$ & $\begin{array}{c}0.0395 * * * \\
(0.0072)\end{array}$ & $\begin{array}{c}0.0965 * * * \\
(0.0089)\end{array}$ & $\begin{array}{l}0.0122 * * \\
(0.0048)\end{array}$ & $\begin{array}{l}-0.0023 \\
(0.0050)\end{array}$ \\
\hline Mother's education & $\begin{array}{l}-0.0035^{*} \\
(0.0021)\end{array}$ & $\begin{array}{c}0.0027 \\
(0.0035)\end{array}$ & $\begin{array}{c}0.0015 \\
(0.0014)\end{array}$ & $\begin{array}{l}-0.0013 \\
(0.0009)\end{array}$ \\
\hline Father's education & $\begin{array}{l}-0.0011 \\
(0.0013)\end{array}$ & $\begin{array}{c}0.0044 \\
(0.0028)\end{array}$ & $\begin{array}{c}-0.0035^{* * *} \\
(0.0011)\end{array}$ & $\begin{array}{l}-0.0016^{*} \\
(0.0009)\end{array}$ \\
\hline Rural residence at age 14 & $\begin{array}{c}-0.0248 * * * \\
(0.0092)\end{array}$ & $\begin{array}{l}-0.0231 \\
(0.0176)\end{array}$ & $\begin{array}{c}0.0121 \\
(0.0092)\end{array}$ & $\begin{array}{l}0.0112^{*} \\
(0.0063)\end{array}$ \\
\hline $\begin{array}{l}\text { Live with both biological } \\
\text { parents at age } 14\end{array}$ & $\begin{array}{c}0.0315^{* * *} \\
(0.0088)\end{array}$ & $\begin{array}{c}0.0434 * * * \\
(0.0159)\end{array}$ & $\begin{array}{c}0.0405 * * * \\
(0.0110)\end{array}$ & $\begin{array}{l}0.0131^{* *} \\
(0.0058)\end{array}$ \\
\hline $\begin{array}{l}\text { Library card in household at } \\
\text { age } 14\end{array}$ & $\begin{array}{c}-0.0309 * * * \\
(0.0086)\end{array}$ & $\begin{array}{c}0.0071 \\
(0.0173)\end{array}$ & $\begin{array}{l}-0.0125 \\
(0.0075)\end{array}$ & $\begin{array}{c}-0.0115^{* *} \\
(0.0049)\end{array}$ \\
\hline $\begin{array}{l}\text { Magazines in household at age } \\
14 \\
\text { Newspapers in household at } \\
\text { age } 14\end{array}$ & $\begin{array}{c}0.0224 * * \\
(0.0095) \\
-0.0026 \\
(0.0134)\end{array}$ & $\begin{array}{c}0.0502 * * * \\
(0.0182) \\
0.0057 \\
(0.0175)\end{array}$ & $\begin{array}{c}0.0067 \\
(0.0074) \\
0.0247 * * \\
(0.0109)\end{array}$ & $\begin{array}{c}0.0046 \\
(0.0050) \\
0.0031 \\
(0.0070)\end{array}$ \\
\hline \multicolumn{5}{|l|}{$\begin{array}{l}\text { Labor market entrance state } \\
\text { characteristics }\end{array}$} \\
\hline Unemployment rate & $\begin{array}{l}-0.6763 \\
(0.5623)\end{array}$ & $\begin{array}{c}-1.6350 * * * \\
(0.4026)\end{array}$ & $\begin{array}{c}0.1505 \\
(0.2989)\end{array}$ & $\begin{array}{c}0.2105 \\
(0.2063)\end{array}$ \\
\hline Poverty rate & $\begin{array}{c}0.2980 \\
(0.2925)\end{array}$ & $\begin{array}{l}0.6592^{*} \\
(0.3287)\end{array}$ & $\begin{array}{l}0.4366^{*} \\
(0.2584)\end{array}$ & $\begin{array}{c}0.2600 \\
(0.1683)\end{array}$ \\
\hline College degree & $\begin{array}{l}-0.4067 \\
(0.3608)\end{array}$ & $\begin{array}{c}0.2462 \\
(0.3298)\end{array}$ & $\begin{array}{l}-0.2033 \\
(0.2474)\end{array}$ & $\begin{array}{l}-0.0715 \\
(0.1621)\end{array}$ \\
\hline Age & $\begin{array}{c}0.0012 \\
(0.0068)\end{array}$ & $\begin{array}{c}0.0134 \\
(0.0095)\end{array}$ & $\begin{array}{l}-0.0038 \\
(0.0070)\end{array}$ & $\begin{array}{c}0.0017 \\
(0.0048)\end{array}$ \\
\hline Private worker & $\begin{array}{c}0.2423 \\
(0.2425)\end{array}$ & $\begin{array}{c}0.4452 \\
(0.3852)\end{array}$ & $\begin{array}{c}0.2086 \\
(0.1545)\end{array}$ & $\begin{array}{l}-0.0301 \\
(0.1396)\end{array}$ \\
\hline Unweighted observations & 68,464 & 79,806 & 83,489 & 82,179 \\
\hline
\end{tabular}

Notes: All models are estimated with least squares (continuous variables) or a linear probability model (binary variables) and control for indicators for missing covariates, labor market entrance state fixed effects, and labor market entrance year fixed effects. AFQT denotes age-standardized Armed Forces Qualification Test. NLSY79 sample weights applied. Standard errors are clustered around the labor market entrance state and reported in parentheses. 
${ }^{1} \mathrm{ESI}=$ Employer-sponsored health insurance offer.

$* * * ; * * ;=$ statistically different from zero at the $1 \% ; 5 \% ; 10 \%$ level. 
Supplementary Appendix Table 13B. The persistent effect of high cost mandates at labor market entrance on labor market outcomes showing all coefficient estimates: NLSY79 women 1979-2012

\begin{tabular}{|c|c|c|c|c|}
\hline Outcome: & ESI $^{1}$ & Log(wages) & Log(weeks) & Full-time \\
\hline Sample proportion/mean & 0.761 & 16.68 & 43.95 & 0.724 \\
\hline High cost mandates & $\begin{array}{l}-0.0122 \\
(0.0074)\end{array}$ & $\begin{array}{c}-0.0272 * * * \\
(0.0089)\end{array}$ & $\begin{array}{c}0.0027 \\
(0.0088)\end{array}$ & $\begin{array}{c}-0.0234 * * * \\
(0.0075)\end{array}$ \\
\hline $\begin{array}{l}\text { High cost mandates } \times \\
\text { potential experience }\end{array}$ & $\begin{array}{c}0.0005 \\
(0.0004)\end{array}$ & $\begin{array}{c}0.0022 * * * \\
(0.0005)\end{array}$ & $\begin{array}{l}-0.0004 \\
(0.0003)\end{array}$ & $\begin{array}{c}0.0007 \\
(0.0004)\end{array}$ \\
\hline Potential experience & $\begin{array}{c}0.0077 * * * \\
(0.0009)\end{array}$ & $\begin{array}{c}0.0121 * * * \\
(0.0014)\end{array}$ & $\begin{array}{c}0.0145^{* * *} \\
(0.0011)\end{array}$ & $\begin{array}{c}0.0036 * * * \\
(0.0007)\end{array}$ \\
\hline \multicolumn{5}{|l|}{ Personal characteristics } \\
\hline $\begin{array}{l}\text { Age at labor market } \\
\text { entrance }\end{array}$ & $\begin{array}{c}0.0016 \\
(0.0036)\end{array}$ & $\begin{array}{l}0.0142 * * \\
(0.0062)\end{array}$ & $\begin{array}{c}0.0043 \\
(0.0037)\end{array}$ & $\begin{array}{c}-0.0071 * * \\
(0.0034)\end{array}$ \\
\hline $\begin{array}{l}\text { High school at labor market } \\
\text { entrance }\end{array}$ & $\begin{array}{c}0.1079 * * * \\
(0.0160)\end{array}$ & $\begin{array}{c}0.1226^{* * * *} \\
(0.0232)\end{array}$ & $\begin{array}{c}0.2147 * * * \\
(0.0153)\end{array}$ & $\begin{array}{c}0.0567 * * * \\
(0.0182)\end{array}$ \\
\hline $\begin{array}{l}\text { Some college at labor market } \\
\text { entrance }\end{array}$ & $\begin{array}{c}0.1239 * * * \\
(0.0243)\end{array}$ & $\begin{array}{c}0.1871 * * * \\
(0.0372)\end{array}$ & $\begin{array}{c}0.2574 * * * \\
(0.0230)\end{array}$ & $\begin{array}{c}0.0772 * * * \\
(0.0249)\end{array}$ \\
\hline $\begin{array}{l}\text { College at labor market } \\
\text { entrance }\end{array}$ & $\begin{array}{c}0.1551 * * * \\
(0.0303)\end{array}$ & $\begin{array}{c}0.3390 * * * \\
(0.0559)\end{array}$ & $\begin{array}{c}0.2598 * * * \\
(0.0325)\end{array}$ & $\begin{array}{c}0.0958 * * * \\
(0.0307)\end{array}$ \\
\hline African American & $\begin{array}{c}0.0438 * * * \\
(0.0093)\end{array}$ & $\begin{array}{c}0.0483 * * * \\
(0.0148)\end{array}$ & $\begin{array}{c}-0.0344 * * * \\
(0.0114)\end{array}$ & $\begin{array}{c}0.0471^{* * *} \\
(0.0147)\end{array}$ \\
\hline Hispanic & $\begin{array}{l}0.0220^{*} \\
(0.0117)\end{array}$ & $\begin{array}{c}0.1117 * * * \\
(0.0325)\end{array}$ & $\begin{array}{c}0.0207 \\
(0.0158)\end{array}$ & $\begin{array}{l}0.0251^{*} \\
(0.0146)\end{array}$ \\
\hline $\begin{array}{l}\text { Age-adjusted AFQT } \\
\text { score }\end{array}$ & $\begin{array}{c}0.0408 * * * \\
(0.0066)\end{array}$ & $\begin{array}{c}0.1269 * * * \\
(0.0121)\end{array}$ & $\begin{array}{c}0.0405 * * * \\
(0.0078)\end{array}$ & $\begin{array}{c}0.0044 \\
(0.0079)\end{array}$ \\
\hline Mother's education & $\begin{array}{l}-0.0023 \\
(0.0015)\end{array}$ & $\begin{array}{c}0.0046 \\
(0.0033)\end{array}$ & $\begin{array}{l}-0.0008 \\
(0.0020)\end{array}$ & $\begin{array}{l}-0.0034^{*} \\
(0.0020)\end{array}$ \\
\hline Father's education & $\begin{array}{l}-0.0018 \\
(0.0013)\end{array}$ & $\begin{array}{l}0.0051^{* *} \\
(0.0025)\end{array}$ & $\begin{array}{l}-0.0004 \\
(0.0019)\end{array}$ & $\begin{array}{c}-0.0050^{* * *} \\
(0.0014)\end{array}$ \\
\hline Rural residence at age 14 & $\begin{array}{l}-0.0021 \\
(0.0095)\end{array}$ & $\begin{array}{l}-0.0278 \\
(0.0206)\end{array}$ & $\begin{array}{c}0.0071 \\
(0.0086)\end{array}$ & $\begin{array}{l}-0.0034 \\
(0.0094)\end{array}$ \\
\hline $\begin{array}{l}\text { Live with both biological } \\
\text { parents at age } 14\end{array}$ & $\begin{array}{c}0.0339 * * * \\
(0.0120)\end{array}$ & $\begin{array}{c}0.0241 \\
(0.0170)\end{array}$ & $\begin{array}{c}0.0199 \\
(0.0119)\end{array}$ & $\begin{array}{c}0.0064 \\
(0.0096)\end{array}$ \\
\hline $\begin{array}{l}\text { Library card in household at age } \\
14\end{array}$ & $\begin{array}{c}0.0180 \\
(0.0122)\end{array}$ & $\begin{array}{l}0.0370^{* *} \\
(0.0160)\end{array}$ & $\begin{array}{c}0.0128 \\
(0.0111)\end{array}$ & $\begin{array}{l}-0.0028 \\
(0.0081)\end{array}$ \\
\hline $\begin{array}{l}\text { Magazines in household at age } \\
14 \\
\text { Newspapers in household at age } \\
14\end{array}$ & $\begin{array}{c}0.0066 \\
(0.0093) \\
0.0114 \\
(0.0173) \\
\end{array}$ & $\begin{array}{c}0.0039 \\
(0.0143) \\
0.0140 \\
(0.0207) \\
\end{array}$ & $\begin{array}{c}0.0019 \\
(0.0099) \\
0.0208 \\
(0.0129) \\
\end{array}$ & $\begin{array}{c}-0.0133 * * \\
(0.0066) \\
0.0232 * \\
(0.0120) \\
\end{array}$ \\
\hline \multicolumn{5}{|l|}{$\begin{array}{l}\text { Labor market entrance state } \\
\text { characteristics }\end{array}$} \\
\hline Unemployment rate & $\begin{array}{l}-0.0419 \\
(0.5565)\end{array}$ & $\begin{array}{l}-1.4517 \\
(0.9948)\end{array}$ & $\begin{array}{l}-0.4771 \\
(0.4953)\end{array}$ & $\begin{array}{l}-0.9253^{*} \\
(0.4931)\end{array}$ \\
\hline Poverty rate & $\begin{array}{c}0.3518 \\
(0.3588)\end{array}$ & $\begin{array}{l}0.1145 \\
(0.4149)\end{array}$ & $\begin{array}{l}-0.2750 \\
(0.2947)\end{array}$ & $\begin{array}{l}-0.1728 \\
(0.2829)\end{array}$ \\
\hline College degree & $\begin{array}{l}-0.1540 \\
(0.2251)\end{array}$ & $\begin{array}{l}-0.4966 \\
(0.3605)\end{array}$ & $\begin{array}{l}-0.5191 * * \\
(0.2225)\end{array}$ & $\begin{array}{l}-0.0609 \\
(0.2414)\end{array}$ \\
\hline Age & $\begin{array}{l}-0.0074 \\
(0.0053)\end{array}$ & $\begin{array}{c}0.0250 * * \\
(0.0120)\end{array}$ & $\begin{array}{l}0.0046 \\
(0.0059)\end{array}$ & $\begin{array}{c}0.0036 \\
(0.0067)\end{array}$ \\
\hline Private worker & $\begin{array}{c}0.2741 \\
(0.2780)\end{array}$ & $\begin{array}{c}0.1856 \\
(0.3180)\end{array}$ & $\begin{array}{l}-0.4559^{*} \\
(0.2409)\end{array}$ & $\begin{array}{l}-0.1866 \\
(0.2508)\end{array}$ \\
\hline Unweighted observations & 64,163 & 76,596 & 80,012 & 78,855 \\
\hline
\end{tabular}

Notes: All models are estimated with least squares (continuous variables) or a linear probability model (binary variables) and control for indicators for missing covariates, labor market entrance state fixed effects, and labor market entrance year fixed effects. AFQT denotes age-standardized Armed Forces Qualification Test. NLSY79 sample weights applied. Standard errors are clustered around the labor market entrance state and reported in parentheses. 
${ }^{1} \mathrm{ESI}=$ Employer-sponsored health insurance offer.

$* * * ; * * ;=$ statistically different from zero at the $1 \% ; 5 \% ; 10 \%$ level. 
Supplementary Appendix Table 14. The persistent effect of high cost mandates at labor market entrance on ESI and labor market outcomes removing survey weights: Current Population Survey 1976-2013

\begin{tabular}{|c|c|c|c|c|}
\hline Outcome: & ESI $^{1}$ & Log(wages) & Log(weeks) & Full-time \\
\hline \multicolumn{5}{|l|}{ Men } \\
\hline $\begin{array}{l}\text { Unweighted sample } \\
\text { proportion/mean }\end{array}$ & 0.759 & 18.11 & 44.66 & 0.867 \\
\hline High cost mandates & $\begin{array}{c}-0.0266 * * * \\
(0.0038)\end{array}$ & $\begin{array}{c}-0.0476 * * * \\
(0.0065)\end{array}$ & $\begin{array}{c}-0.0369 * * * \\
(0.0078)\end{array}$ & $\begin{array}{c}-0.0339 * * * \\
(0.0043)\end{array}$ \\
\hline $\begin{array}{l}\text { High cost mandates } \times \\
\text { potential experience }\end{array}$ & $\begin{array}{c}0.0021 * * * \\
(0.0003)\end{array}$ & $\begin{array}{c}0.0042 * * * \\
(0.0005)\end{array}$ & $\begin{array}{c}0.0030^{* * * *} \\
(0.0004)\end{array}$ & $\begin{array}{c}0.0029 * * * \\
(0.0004)\end{array}$ \\
\hline Unweighted observations & 222,603 & 310,973 & 332,131 & 332,131 \\
\hline \multicolumn{5}{|l|}{ Women } \\
\hline $\begin{array}{l}\text { Unweighted sample } \\
\text { proportion/mean }\end{array}$ & 0.708 & 14.32 & 42.19 & 0.708 \\
\hline High cost mandates & $\begin{array}{l}-0.0224 * * * \\
(0.0045)\end{array}$ & $\begin{array}{c}-0.0331 * * * \\
(0.0052)\end{array}$ & $\begin{array}{l}-0.0141 \\
(0.0086)\end{array}$ & $\begin{array}{c}-0.0174 * * * \\
(0.0046)\end{array}$ \\
\hline $\begin{array}{l}\text { High cost mandates } \times \\
\text { potential experience }\end{array}$ & $\begin{array}{c}0.0018^{* * * *} \\
(0.0002) \\
\end{array}$ & $\begin{array}{c}0.0030 * * * \\
(0.0004)\end{array}$ & $\begin{array}{c}0.0014 * * * \\
(0.0003)\end{array}$ & $\begin{array}{c}0.0017 * * * \\
(0.0003) \\
\end{array}$ \\
\hline Unweighted observations & 176,761 & 278,728 & 290,164 & 290,164 \\
\hline
\end{tabular}

Notes: All models estimated with least squares (continuous variables) or a linear probability model (binary variables), and control for demographics, state fixed effects, labor market entrance year fixed effects, and year fixed effects. CPS sample weights applied. Standard errors are clustered around the state and reported in parentheses. ${ }^{1} \mathrm{ESI}=$ Hold employer-sponsored health insurance. This variable is only available 1980-2013. $* * * ; * ; *=$ statistically different from zero at the $1 \% ; 5 \% ; 10 \%$ level. 


\section{References:}

Abraham, Jean Marie, and Roger Feldman. 2010. "Taking up or turning down: New estimates of household demand for employer-sponsored health insurance." Inquiry 47 (1):17-32.

Acs, G, S H Long, M S Marquis, and P F Short. 1996. "Self-insured employer health plans: prevalence, profile, provisions, and premiums." Health Affairs 15 (2):266-278.

Akosa Antwi, Yaa, Asako S. Moriya, and Kosali I. Simon. 2015. "Access to health insurance and the use of inpatient medical care: Evidence from the Affordable Care Act young adult mandate." Journal of Health Economics 39:171-187.

Altonji, Joseph G., Lisa B. Kahn, and Jamin D. Speer. 2016. "Cashier or Consultant? Entry Labor Market Conditions, Field of Study, and Career Success." Journal of Labor Economics 34 (S1):S361-S401.

Andersen, Martin. 2015. "Heterogeneity and the effect of mental health parity mandates on the labor market." Journal of Health Economics 43:74-84.

Angrist, Joshua D., and J Pischke. 2009. Mostly Harmless Econometrics: An Empiricist's Companion. Princeton, NJ: Princeton University Press. Book. Original edition, Princeton University Press.

Baicker, Katherine, and Amitabh Chandra. 2006. "The labor market effects of rising health insurance premiums." Journal of Labor Economics 24 (3):609-634.

Bailey, James. 2014. "The effect of health insurance benefit mandates on premiums." Eastern Economic Journal 40 (1):119-127.

Bailey, James, and Nathan Blascak. 2016. "The effect of state health insurance benefit mandates on premiums and employee contributions." Applied Economics Letters:1-5.

Bailey, James, and Douglas Webber. 2016. "Health Insurance Benefit Mandates and Firm Size Distribution." Journal of Risk and Insurance In Press.

Bao, Yuhua, and Roland Sturm. 2004. "The Effects of State Mental Health Parity Legislation on Perceived Quality of Insurance Coverage, Perceived Access to Care, and Use of Mental Health Specialty Care." Health Services Research 39 (5):1361-1378.

Bewley, Truman F. 1998. "Why not cut pay?" European Economic Review 42 (3):459-490.

Blau, F., and L. Kahn. 2007. "Changes in the Labor supply behavior of married women: 19802000." Journal of Labor Economics 25 (3):393-438.

Buchmueller, Thomas C, John DiNardo, and Robert G Valletta. 2011. "The effect of an employer health insurance mandate on health insurance coverage and the demand for labor: Evidence from Hawaii." American Economic Journal: Economic Policy 3 (4):2551 .

Bunce, V.C., and J.P. Wieske. 2010. Health Insurance Mandates in the States 2010. Washington, DC: Council for Affordable Health Insurance.

Claxton, G., M. Rae, M. Long, A. Damico, H. Whitmore, and G. Foster. 2017. "Health Benefits In 2017: Stable Coverage, Workers Faced Considerable Variation In Costs." Health Affairs 36 (10):1838-1847.

Clemens, Jeffrey, and David M. Cutler. 2014. "Who pays for public employee health costs?" Journal of Health Economics 38:65-76.

Cooper, Philip F, and Jessica Vistnes. 2003. "Workers' decisions to take-up offered health insurance coverage: assessing the importance of out-of-pocket premium costs." Medical Care 41 (7):III-35-III-43.

Courtemanche, Charles J., and Daniela Zapata. 2014. "Does Universal Coverage Improve Health? The Massachusetts Experience." Journal of Policy Analysis and Management 33 (1):36-69. 
Cseh, Attila. 2008. "Labor market consequences of state mental health parity mandates." Forum for Health Economics \& Policy 11 (2).

Cutler, D. M., and J. Gruber. 1996. "Does public insurance crowd out private insurance?" Quarterly Journal of Economics 111 (2):391-430.

Cutler, David M, and Brigitte C Madrian. 1998. "Labor Market Responses to Rising Health Insurance Costs: Evidence on Hours Worked." The Rand Journal of Economics:509530.

Dave, D., and S. Mukerjee. 2011. "Mental health parity legislation, cost-sharing and substanceabuse treatment admissions." Health Economics 20 (2):161-183.

Depew, B., and J. Bailey. 2015. "Did the Affordable Care Act's dependent coverage mandate increase premiums?" Journal of Health Economics 41:1-14.

Ellwood, David T. 1982. "Teenage unemployment: Permanent scars or temporary blemishes?" In The youth labor market problem: Its nature, causes, and consequences, 349-390. University of Chicago Press.

Flood, S., M. King, S. Ruggles, and J.R. Warren. 2017. Integrated public use microdata series, Current Population Survey. Minneapolis, MN.

Gabel, Jon R, and Gail A Jensen. 1992. "Can a universal coverage system temper the underwriting cycle?" Inquiry:249-262.

Genda, Yuji, Ayako Kondo, and Souichi Ohta. 2010. "Long-Term Effects of a Recession at Labor Market Entry in Japan and the United States." Journal of Human Resources 45 (1):157-196.

Greene, William. 2004. "The behaviour of the maximum likelihood estimator of limited dependent variable models in the presence of fixed effects." The Econometrics Journal 7 (1):98-119.

Gruber, J. 1994a. "The Incidence of Mandated Maternity Benefits." American Economic Review 84 (3):622-641.

Gruber, J. 1994b. "State-Mandated Benefits and Employer-Provided Health-Insurance." Journal of Public Economics 55 (3):433-464.

Gruber, Jonathan, and Kosali Simon. 2008. "Crowd-out 10 years later: Have recent public insurance expansions crowded out private health insurance?" Journal of Health Economics 27 (2):201-217.

Hoynes, H., D. L. Miller, and J. Schaller. 2012. "Who Suffers During Recessions?" Journal of Economic Perspectives 26 (3):27-47.

Jensen, G. A., and M. A. Morrisey. 1999. "Employer-sponsored health insurance and mandated benefit laws." The Milbank Quarterly 77 (4):425-59.

Jovanovic, Boyan. 1979. "Job matching and the theory of turnover." The Journal of Political Economy:972-990.

Kaestner, Robert, and Kosali Ilayperuma Simon. 2002. "Labor market consequences of state health insurance regulation." Industrial \& Labor Relations Review 56 (1):136-159.

Kahn, Lisa B. 2010. "The long-term labor market consequences of graduating from college in a bad economy." Labour Economics 17 (2):303-316.

Klick, J., and T. Stratmann. 2006. "Subsidizing addiction: Do state health insurance mandates increase alcohol consumption?" Journal of Legal Studies 35 (1):175-198.

Kondo, Ayako. 2015. "Differential effects of graduating during a recession across gender and race." IZA Journal of Labor Economics 4 (1):1-24.

Lahey, Joanna N. 2012. "The efficiency of a group-specific mandated benefit revisited: The effect of infertility mandates." Journal of Policy Analysis and Management 31 (1):6392. 
Laugesen, Miriam J, Rebecca R Paul, Harold S Luft, Wade Aubry, and Theodore G Ganiats. 2006. "A comparative analysis of mandated benefit laws, 1949-2002." Health Services Research 41 (3p2):1081-1103.

Litow, M. 2002. Our own worst enemies: Explaining premium increases in the individual health insurance market. In Issues and Answers. Alexandria, VA: Council for Affordable Health Insurance.

Lubotsky, Darren, and Craig A. Olson. 2015. "Premium copayments and the trade-off between wages and employer-provided health insurance." Journal of Health Economics 44:6379.

Maclean, J. C. 2014. "Does leaving school in an economic downturn impact access to employersponsored health insurance?" IZA Journal of Labor Policy 3 (1):1-27.

Maclean, J. C., I. Popovici, and E. Stern. 2017. Health Insurance Expansions and Provider Behavior: Evidence from Substance Use Disorder Providers. In National Bureau of Economic Research Working Paper Series. Cambridge, MA.

Maclean, J.C. 2013. "The health effects of leaving school in a bad economy." Journal of Health Economics 32 (5):951-964.

McDonnell, Patricia, Abbie Guttenberg, Leonard Greenberg, and Ross H. Arnett. 1986. "Selfinsured health plans." Health Care Financing Review 8 (2):1-16.

Meer, Jonathan, and Jeremy West. 2011.

Monheit, A., J. Rizzo, Joel Cantor, and J Abramo. 2007. Assessing the Impact of Mandated Health Insurance Benefifi ts on Cost and Coverage. Rutgers, NJ: Rutgers Center for State Health Policy.

Morrisey, M.A. 2014. "State Insurance Mandates in the USA." In Encyclopedia of Health Economics, edited by A J Culyer, 348-351. San Diego, CA: Elsevier.

National Council of State Legislatures. 2017. "State laws mandating or regulating mental health benefits." [Website], accessed May 27 2017. http://www.ncsl.org/research/health/mentalhealth-benefits-state-mandates.aspx.

Neumark, D. 2002. "Youth labor markets in the United States: Shopping around vs. staying put." Review of Economics and Statistics 84 (3):462-482.

Oreopoulos, Philip, Till von Wachter, and Andrew Heisz. 2012. "The Short- and Long-Term Career Effects of Graduating in a Recession." American Economic Journal: Applied Economics 4 (1):1-29.

Oyer, Paul. 2006. "Initial Labor Market Conditions and Long-Term Outcomes for Economists." The Journal of Economic Perspectives 20 (3):143-160.

Pacula, Rosalie Liccardo, and Roland Sturm. 2000. "Mental health parity legislation: much ado about nothing?" Health Services Research 35 (1 Pt 2):263.

Popovici, I., J. C. Maclean, and M. French. 2017. The effects of health insurance parity laws for substance use disorder treatment on traffic fatalities: Evidence of unintended benefits. In National Bureau of Economic Research Working Paper Series. Cambridge, MA.

Sloan, Frank A., and Christopher J. Conover. 1998. "Effects of State Reforms on Health Insurance Coverage of Adults." Inquiry 35 (3):280-293.

Sturm, Roland. 2000. "State parity legislation and changes in health insurance and perceived access to care among individuals with mental illness: 1996-1998." The Journal of Mental Health Policy and Economics 3 (4):209-213.

Summers, Lawrence H. 1989. "Some simple economics of mandated benefits." The American Economic Review 79 (2):177-183.

Topel, Robert H, and Michael P Ward. 1992. "Job Mobility and the Careers of Young Men." The Quarterly Journal of Economics:439-479. 
Webber, D. A. 2015. "Firm market power and the earnings distribution." Labour Economics 35:123-134. 